\title{
Flame Characteristics and Emissions in Flameless Combustion Under Gas Turbine Relevant Conditions
}

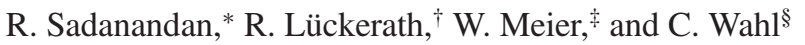 \\ DLR, German Aerospace Center, 70569 Stuttgart, Germany
}

DOI: $10.2514 / 1.50302$

\begin{abstract}
The combustion behavior of natural gas flames with $\mathrm{H}_{2}$ as an admixture is investigated in an optically accessible combustor operating under gas turbine relevant conditions. $\mathrm{OH}^{*}$ chemiluminescence imaging and planar laserinduced fluorescence measurements of $\mathrm{OH}$ were performed along with exhaust gas analysis to investigate the influence of various parameters like mixture composition, degree of premixing, and velocities on the pollutant emissions. The results show that the degree of premixing along with the recirculation rate of the burned gases plays an important role in $\mathrm{NO}_{x}$ and $\mathrm{CO}$ emissions. Compared with pure natural gas fired flames, the ones with $\mathrm{H}_{2}$ admixture burned closer to the burner due to an increased reactivity. Under such conditions, a low emissions operating range can be achieved either by increasing the jet velocities or by reducing the degree of premixing. Both methods favor $\mathrm{NO}_{x}$ reduction due to the suppression of local peak flame temperatures. The optimum combination of degree of premixing and jet velocity should lead to a recirculation and mixing rate such that the resulting ignition delay is long enough to promote mixing of the fresh fuel/air with the burned gases before the flame reactions but short enough to ensure a stable operation of the burner. At the same time, combustor residence times should be short in order to reduce the thermal-NO formation but long enough to enable complete combustion.
\end{abstract}

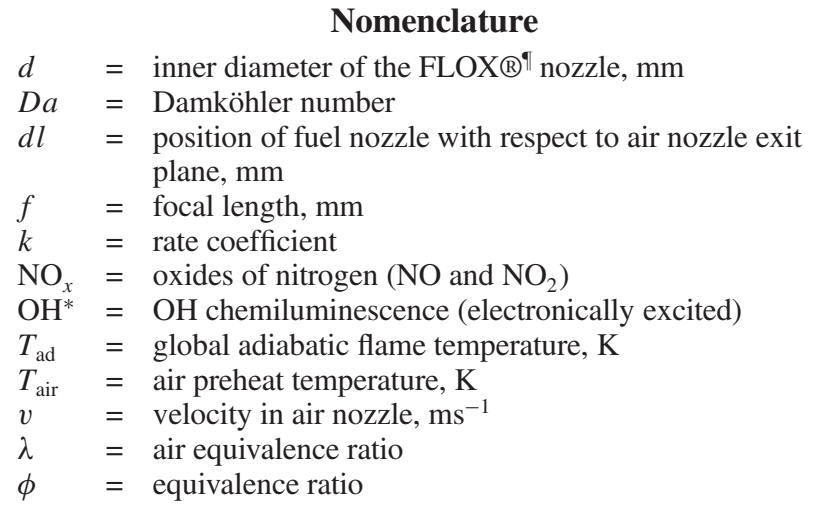

\section{Introduction}

$\mathbf{W}$ ITH the ever increasing demand for the development of energy systems that are environment friendly and efficient, researchers around the world have made significant advances in the last decades in the technology and product development of power generation systems like gas turbines (GTs) that burn fossil fuels. This includes both land-based and aero-GT engines. Some of the developments in the land-based GT engines include lean premixed prevaporized combustion, staged combustion, rich burn/quick quench/lean burn, reheat, catalytic combustion, and more. In this regard, flameless combustion (FC) is a very promising combustion

Received 12 July 2010; revision received 15 April 2011; accepted for publication 23 April 2011. Copyright (C) 2011 by DLR, German Aerospace Center. Published by the American Institute of Aeronautics and Astronautics, Inc., with permission. Copies of this paper may be made for personal or internal use, on condition that the copier pay the $\$ 10.00$ per-copy fee to the Copyright Clearance Center, Inc., 222 Rosewood Drive, Danvers, MA 01923; include the code 0748-4658/11 and \$10.00 in correspondence with the CCC.

*Scientist, Institute of Combustion Technology, Combustion Diagnostics Department, Pfaffenwaldring 38-40; Rajesh.Sadanandan@dlr.de.

${ }^{\dagger}$ Scientist, Institute of Combustion Technology, Combustion Diagnostics Department, Pfaffenwaldring 38-40; Rainer.Lueckerath@dlr.de.

${ }^{*}$ Head of the Department, Institute of Combustion Technology, Combustion Diagnostics Department, Pfaffenwaldring 38-40; Wolfgang. Meier@dlr.de.

${ }^{\S}$ Scientist, Institute of Combustion Technology, Chemical Analysis Department, Pfaffenwaldring 38-40; Claus.Wah1@dlr.de. technique to reduce pollutant levels in view of the stringent emission norms that face us today.

FC, under optimized conditions, occurs with a low visible reaction zone and pollutant emissions. It results from an intense mixing of recirculating burned gases with fresh gas, and many variations of this combination exist in technologies like exhaust gas recirculation $[1,2]$, high-temperature air combustion [3] , stagnation-point reverse flow [4], and moderate and intense low oxygen dilution (MILD) combustion [5]. The FC technique, which was first exploited by Wünning and Wünning [6], works on the principle that if the recirculation rate is high enough to entrain the burned gases into the fresh reactants to produce mixture temperatures higher than the autoignition temperature of the mixture, the combustion is initiated at many locations simultaneously with reduced combustion temperatures and less combustion noise [5]. The recirculation rate is a critical parameter in FC, as it has a strong impact on the mixing of the fresh fuel/air with the burned gases, and thereby the content of products $\mathrm{CO}_{2}$ and $\mathrm{H}_{2} \mathrm{O}$ in the mixture. The higher heat capacity of the products helps in lowering the flame heat and the temperatures locally, thereby playing a significant role in the $\mathrm{NO}_{x}$ reduction process $[2,3]$ as well. Since such combustion under lean conditions can be sustained only by the supply of highly preheated air, for the FC to succeed at high recirculation rates, a certain degree of oxidizer preheating is indispensable. Ideally, the combustion zone will thus be volumetric in nature, with little temperature gradients in the reaction zone, and becomes close to the model of a well-stirred reactor, as the chemical timescales are larger than the turbulent timescales as a result of the strong dilution of the reactants [7].

Although this new combustion technology has been primarily developed and successfully applied for industrial furnaces at atmospheric pressures, the application of this technique to GT engines is not straightforward. GT combustors operate at elevated pressures and temperatures with low pressure losses and maintain high turbine inlet temperatures (TITs) for higher GT cycle efficiency. Lückerath et al. demonstrated the applicability of FC to typical GT conditions and pressures up to 30 bar $[\underline{8}, \underline{9}]$ with natural gas (NG) and hydrogen as fuel. Because of its stability characteristics and low emission rates, the current attempts are also concentrated in extending this technology to aero-GT engines $[10,11]$.

'FLOX® is a registered trademark of WS Wärmeprozesstechnik, GmbH, Renningen, Germany. 
Since the FC takes place with a low luminous reaction zone, identifying it with standard optical methods becomes difficult. In this study, planar laser-induced fluorescence (PLIF) measurements of the hydroxyl radical $(\mathrm{OH})$ were employed to identify the hightemperature zones in addition to chemiluminescence imaging of the electronically excited $\mathrm{OH}$ radical $\left(\mathrm{OH}^{*}\right)$, which acts as a reaction zone marker [12]. The nonintrusive laser-based measurement techniques are advantageous due to their ability to yield twodimensional fields of scalars with high temporal and spatial resolution $[13,14]$ and have been employed by many research groups for investigations in GT-relevant conditions [15-19]. The research work presented in this paper is a continuation of the studies that were reported in [20]. In the current project, the fuel flexibility of this burner is investigated under GT-relevant conditions with different mixtures of NG and hydrogen $\left(\mathrm{H}_{2}\right)$. The aim of the project is to identify the stable low emission operating ranges and to study the influence of $\mathrm{H}_{2}$ admixture to $\mathrm{NG}$ on the combustion behavior in $\mathrm{FC}$ mode. A further goal is the generation of an experimental database for the validation and optimization of numerical simulation codes. The investigations were carried out at the high-pressure test rig facility at the German Aerospace Center (DLR) in Stuttgart, in which a FLOX (flameless oxidation) burner was installed and operated at pressures up to 20 bar. The results presented in this paper include $\mathrm{OH}-\mathrm{PLIF}, \mathrm{OH}^{*}$ chemiluminescence measurements, and monitoring of exhaust gas emissions by analytical methods. The paper focuses mainly on the influence of various parameters like fuel composition, flow velocities, and air preheat temperature on the pollutant emissions on FC under GT-relevant conditions.

\section{Experiment}

\section{A. Burner and Combustion Chamber}

The burner used in the current research works in a flameless oxidation or FC mode. The burner originally developed by WS Wärmeprozesstechnik, $\mathrm{GmbH}$, consisted of 12 nozzles, each positioned in a reference circle of $80 \mathrm{~mm}$ through which the air and fuel are injected at high velocities (see Fig. 1). The individual (air) nozzles have a diameter $(d)$ of $4.5 \mathrm{~mm}$ with a coaxial fuel nozzle of $1 \mathrm{~mm}$ in diameter. The position of the fuel nozzle with respect to the exit plane of the air nozzle is variable, thereby enabling different levels of premixing before the fuel/air mixture exits the nozzle. Three different positions $(0,12$, and $24 \mathrm{~mm})$ of the fuel nozzle with respect to the air nozzle exit plane (termed $d l$ in this paper) were investigated in the current studies, where $d l=0 \mathrm{~mm}$ refers to a configuration in which the exit planes of fuel and air nozzle overlap (nonpremixed configuration) and $d l=24 \mathrm{~mm}$ is defined as the standard configuration with a certain degree of premixing. Owing to the short convective distance, complete premixing between the fuel and the air is highly unlikely at the nozzle exit for the $d l=24 \mathrm{~mm}$ configuration. Nevertheless, the nozzle configuration with $d l=24 \mathrm{~mm}$ is hereafter termed premixed for convenience. An ignition burner positioned at the geometrical axis of the burner is used for the initial ignition of the flame.
The original combustor design (circular in cross section) was modified at DLR to meet the demand of the high-pressure operation and to enable optical diagnostic measurements at the FLOX burner. The hexagonal cross section was chosen so that there are only small deviations from the axisymmetric flowfield of the circular crosssectioned burner. The overall dimensions of the combustion chamber are $200 \mathrm{~mm}$ in length and $100 \mathrm{~mm}$ in inner diameter (hexagonal cross section). Each of the six windows of the combustion chamber is equipped with two quartz glass windows in parallel arrangement with an air-cooling channel in between them. More information about the burner and the combustor can be found in [9].

\section{B. High-Pressure Combustion Test Rig}

The combustor was installed at the high-pressure test rig facility (HBK-S) of the DLR Institute of Combustion Technology in Stuttgart. The test rig pressure vessel is equipped with large quartz windows, thereby providing excellent optical access to the combustion chamber. The test rig is also equipped with several probes for the measurement of temperature, absolute pressure, and differential pressures at different locations. The air, supplied by a compressor and preheated to the required experimental conditions, first flows through the air-cooling channels of the quartz windows from downstream of the combustion chamber before entering the plenum of the burner. The combustion air temperature is measured at the plenum of the burner, and the mass flow rate of the air entering the burner is calculated from the pressure drop at the burner inlet ports. The error in mass flow rates is estimated to be 5-7\% [9]. The fuel mass flow rates were regulated with high precision Coriolis flow meters (accuracy of 1\%). A suction probe downstream of the combustion chamber monitored and recorded the exhaust gas concentrations of $\mathrm{NO}$ and $\mathrm{NO}_{2}$ (via UV photometry), $\mathrm{CO}$ (via infrared photometry), and $\mathrm{O}_{2}$ (by paramagnetism) every $5 \mathrm{~s}$ using a conventional exhaust gas analyzer (Asea Brown Boveri).

\section{Operating Conditions}

The main goal of the current studies is to investigate the influence of hydrogen as an admixture to NG on the emission characteristics of a burner operating in flameless oxidation mode at a pressure of 20 bar. For the standard configuration $(d l=24 \mathrm{~mm}, d=4.5 \mathrm{~mm})$, measurements were performed for $\mathrm{H}_{2}$ in addition to $\mathrm{NG}$ in the range from $0-100 \%$ (by volume) in steps of $20 \%$ with equal total thermal power; although this paper concentrates only on 0 and $40 \% \mathrm{H}_{2}$ addition cases. The NG used had a composition of $94 \% \mathrm{CH}_{4}, 2.5 \%$ $\mathrm{C}_{2} \mathrm{H}_{6}, \quad 0.4 \% \quad \mathrm{C}_{3} \mathrm{H}_{8}, \quad 2.3 \% \quad \mathrm{~N}_{2}, 0.7 \% \quad \mathrm{CO}_{2}$, and $0.1 \%$ higher hydrocarbons. For every $\mathrm{NG}$ and $\mathrm{H}_{2}$ composition and mean nozzle exit velocities, the air equivalence ratio $\lambda$ (reciprocal of the equivalence ratio, $\phi$ ) was increased in several steps by decreasing the fuel mass flow until the flame extinguished. Here, the uncertainty of $\lambda$ stems from the uncertainty of the air mass flow rate and was about $\pm 5-7 \%$. Measurements were conducted for air preheat temperatures $\left(T_{\text {air }}\right)$ of 703 and $873 \mathrm{~K}$. For selected cases, the measurements were repeated for $d l=0$ and $12 \mathrm{~mm}$. All the results discussed in the following sections are for $T_{\text {air }}=703 \mathrm{~K}$ unless otherwise specified.

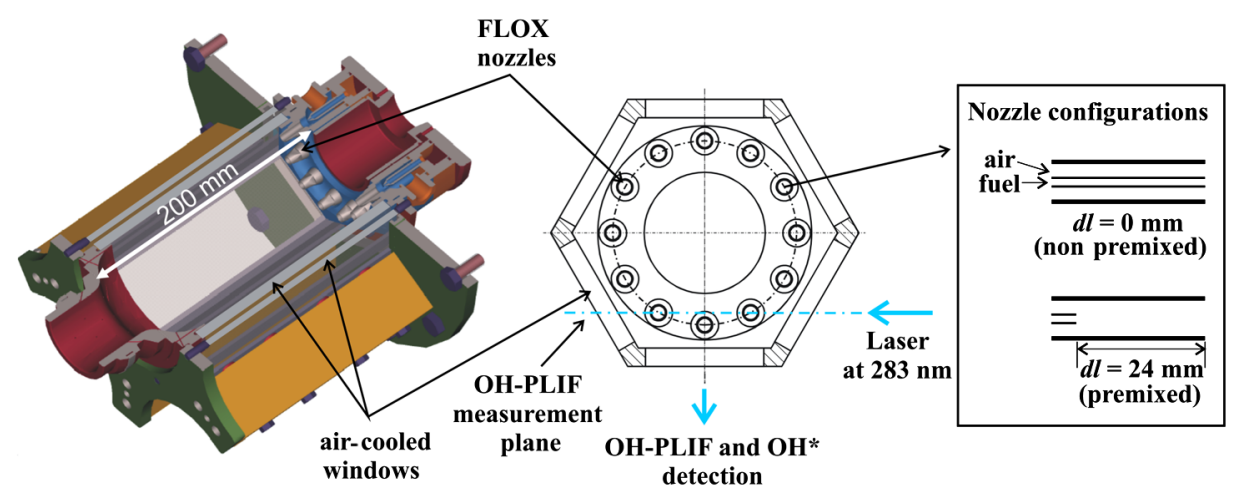

Fig. 1 Three-dimensional drawing of the optically accessible combustion chamber with the FLOX burner (left) and the schematic of the FLOX burner with the OH-PLIF measurement planes marked (right). 
Based on $\lambda$ and $T_{\text {air }}$, the adiabatic flame temperature $\left(T_{\text {ad }}\right)$ can be determined from equilibrium calculations. The overall error in the $T_{\text {ad }}$ estimation was about $\pm 40-70 \mathrm{~K}$, taking into account the errors associated with $\lambda$. The mean nozzle exit velocities were increased by increasing the total mass flow, and thereby increasing the thermal power. The mean velocities in the air nozzle are varied from $83<v<161 \mathrm{~ms}^{-1}$, with different thermal powers of $141-500 \mathrm{~kW}$ and resulting specific heat densities per volume between 4.1514.69 $\mathrm{MWm}^{-3} \mathrm{bar}^{-1}$.

\section{Optical Diagnostic Measurement Techniques and Experimental Setup}

$\mathrm{OH}^{*}$ chemiluminescence and OH-PLIF were used to visualize the size, shape, and position of heat release zone and to identify the hightemperature zones, respectively. A standard OH-PLIF optical setup, as shown in Fig. 2, was used for the current studies.

The UV beam used for the excitation of $\mathrm{OH}$ radicals was provided by a frequency doubled tunable dye laser (Lumonics, HD-500) at $10 \mathrm{~Hz}$ pulse repetition rate that, in turn, was pumped by a flashlamp pumped, frequency doubled Nd:YAG laser (Quanta Ray, DCR-2) at $532 \mathrm{~nm}$. The UV beam had a pulse energy of approximately $4-6 \mathrm{~mJ}$ at the exit of the laser and was tuned to the $Q_{1}(8)$ transition of $\mathrm{OH} A-X$ $(1,0)$ system at approximately $283 \mathrm{~nm}$. The planar sheet formed by a combination of cylindrical lenses $(f=-25 \mathrm{~mm}$ and $f=$ $+750 \mathrm{~mm}$ ) had a height of $55 \mathrm{~mm}$ and approximately $400 \mu \mathrm{m}$ sheet thickness inside the combustor. For selected operating conditions, the sheet optics were translated further downstream to capture the OH-PLIF up to $100 \mathrm{~mm}$ from the nozzle exit. A small portion of the incoming laser beam was directed into $\mathrm{CH}_{4}$ /air reference flame on a matrix burner with the help of a beam splitter, as shown in Fig. 2, and the LIF signal produced by this flame was used for the online monitoring of the excitation line wavelength.

On the detection side, an image-intensified charge-coupled device (CCD) camera (Roper Scientific, $512 \times 512$ pixels) with an achromatic UV lens (Halle, $f / 2, f=100 \mathrm{~mm}$ ) and UV interference filter ( $312 \pm 15 \mathrm{~nm}$, Laser Components, $\mathrm{GmbH}$ ) was used to collect the planar OH-LIF signal from the burner at $90^{\circ}$. The filter also helped in blocking the direct laser scattering at $283 \mathrm{~nm}$. The $\mathrm{OH}-$ LIF images were corrected for laser sheet profile inhomogeneities in postprocessing using the sheet profiles that were imaged simultaneously on a second intensified CCD camera (Roper Scientific, $512 \times 512$ pixels $)$ equipped with a Nikon lens $(f / 4.0, f=50 \mathrm{~mm})$ from a dye cell, as shown in in Fig. 2. The exposure time for the $\mathrm{OH}-$ PLIF and sheet cameras was $400 \mathrm{~ns}$. The ensemble averaged images shown in this paper were obtained from 200 single-shot images of $\mathrm{OH}-\mathrm{PLIF}$ and $\mathrm{OH}^{*}$ captured at approximately $3 \mathrm{~Hz}$. The timing between the laser pulses and the camera exposure was synchronized by means of a pulse delay generator (SRS, Inc., model DG535).

The detection system and the filter combination that were used for the OH-PLIF measurements were also used for the $\mathrm{OH}^{*}$ chemiluminescence imaging. The exposure time in this case was set

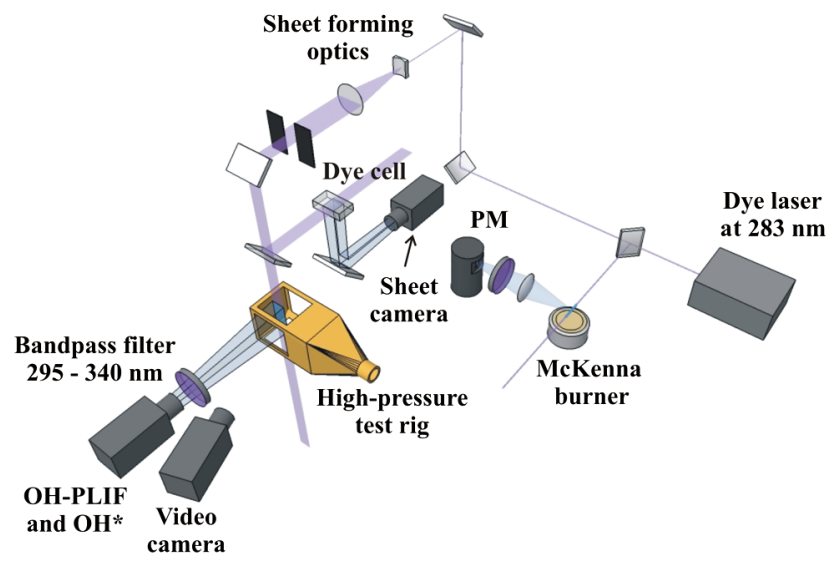

Fig. 2 Schematic of the optical setup used for the OH-PLIF and $\mathrm{OH}^{*}$ chemiluminescence measurements (PM: photomultiplier). to $40 \mu \mathrm{s}$. Since $\mathrm{OH}^{*}$ signals are line-of-sight integrated, the spatial resolution is compromised. However, the $\mathrm{OH}^{*}$ formed mainly in the reaction zone provides information about the position of the reaction zone owing to its very short lifetime (within nanoseconds) [21]. The key $\mathrm{OH}^{*}$ forming reactions [22] are

$$
\begin{gathered}
\mathrm{CH}+\mathrm{O}_{2} \leftrightarrow \mathrm{OH}^{*}+\mathrm{CO} \\
\mathrm{H}+\mathrm{O}+\mathrm{M} \leftrightarrow \mathrm{OH}^{*}+\mathrm{M}
\end{gathered}
$$

In the case of atmospheric flames, most of the $\mathrm{OH}^{*}$ is produced via reaction 1 in the reaction zone. But in the case of high-pressure flames, like the ones in the current studies, the product side of the reaction zone is an important source of $\mathrm{OH}^{*}$ via reaction 2. This is because in the product side, where the $\mathrm{CH}$ radicals are absent, the $\mathrm{OH}^{*}$ is produced by the recombination of $\mathrm{H}$ and $\mathrm{O}$ via reaction 2 . Thus, with increasing pressure, the contribution of the exhaust zone $\mathrm{OH}^{*}$ production significantly increases and the $\mathrm{OH}^{*}$ produced via reaction 1 decreases rapidly in the reaction zone. Moreover, reaction 2 is a three-body reaction, which is greatly enhanced by pressure.

\section{Results and Discussions}

To achieve the FC mode, the recirculation of the combustion products back into the combustion zone is necessary, as emphasized by Wünning and Wünning [6]. In the current design, this is achieved by means of the high momentum of the fuel/air flow through the nozzles, as demonstrated in Fig. 3. The high scalar dissipation at regions closer to the nozzle exit ensures mixing of the fuel and air with the burned gas before it reacts. In the figure, a numerical simulation of the overall axial velocity distribution is shown [9], with streamlines overlapped along a longitudinal plane passing through the air nozzle and the combustor. As a result of the nozzle design and combustor dimensions, the flowfield consists of a large central recirculation zone and a small outer recirculation zone. The location and the size of these recirculation zones were found to be independent of the combustor operating conditions in the simulations.

Combustion in the FC mode is strongly influenced by a complex interplay between a lot of parameters like fuel composition, mixture temperature, mixing rate, residence time, and local equivalence ratio. The different test conditions will have a direct influence on one or more of the aforementioned parameters. Therefore, in order to have a quantitative comparison between different operating conditions, we define the low emissions operating range (termed as LEOR from here afterward) as the range at which the $\mathrm{NO}_{x}\left(\mathrm{NO}\right.$ and $\left.\mathrm{NO}_{2}\right)$ and $\mathrm{CO}$ emission values are less than $10 \mathrm{ppm}$. So, the current section is structured in such a way that the first section identifies the LEOR in terms of the global $\mathrm{NO}_{x}$ and $\mathrm{CO}$ emissions. In the following sections, a detailed investigation of the influence of the individual variables on the behavior of the system in this range is undertaken with the help of $\mathrm{OH}^{*}$ and $\mathrm{OH}-\mathrm{PLIF}$ distributions.

\section{A. Identification of the Low Emissions Operating Range}

Figures $4 \mathrm{a}-4 \mathrm{~d}$ display plots of $\mathrm{NO}_{x}$ (solid lines) and $\mathrm{CO}$ (dashed lines) versus $\lambda$ for variations in $v, d l$, percentage of $\mathrm{H}_{2}$ admixture, and $T_{\text {air }}$. In general, for $d l=24 \mathrm{~mm}, v=90 \mathrm{~ms}^{-1}$, the LEOR exists only at higher $\lambda$ values $(\lambda>2.2)$ where the corresponding global $T_{\text {ad }}$ of the mixture is less than $1700 \mathrm{~K}$. The TITs of the current commercial GTs lie in the range from 1700-1900 K, which implies that for the

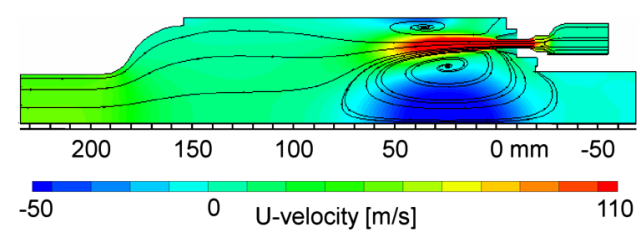

Fig. 3 Simulated axial velocity distribution with streamlines overlapped along a longitudinal plane through the nozzle and the combustor axis [9]. 


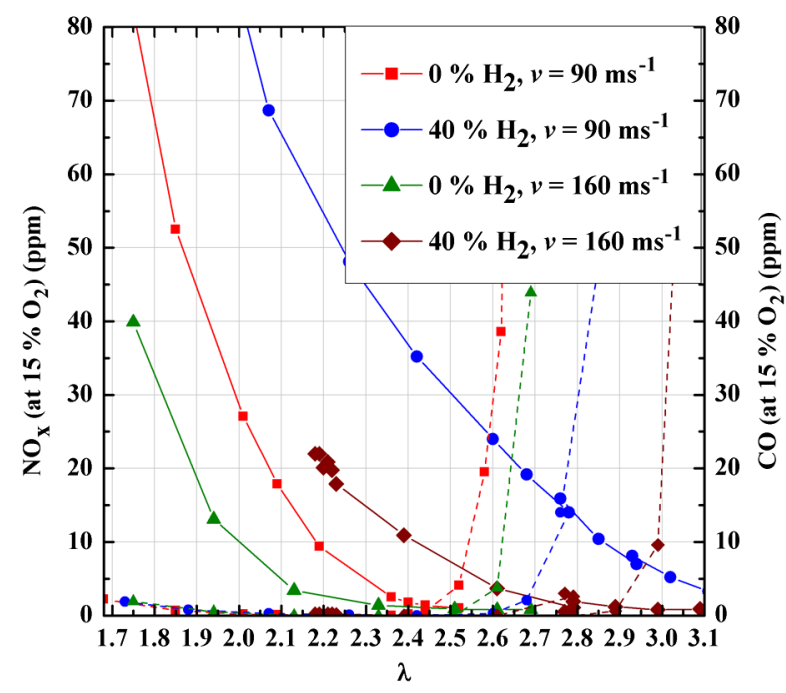

a)

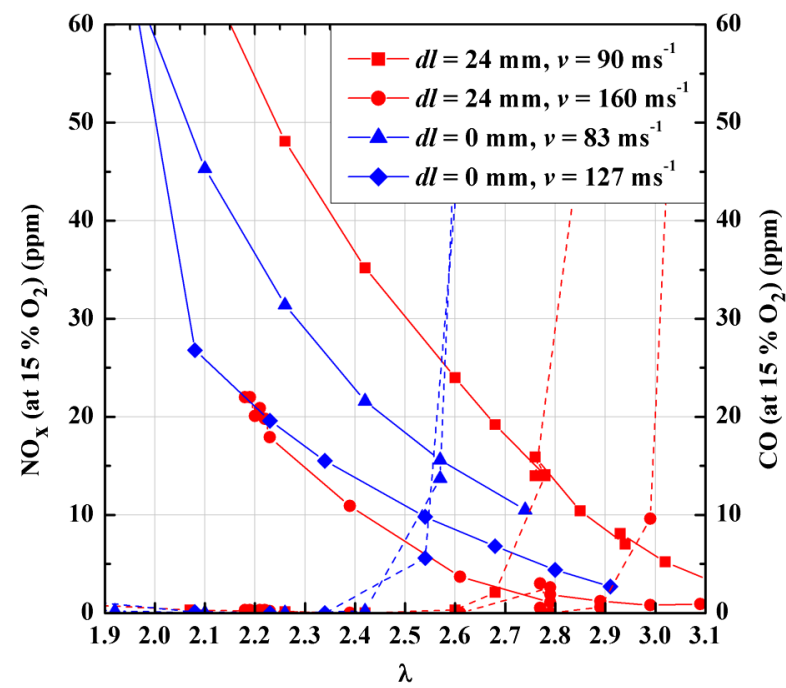

c)

Fig. $4 \mathrm{NO}_{x}$ (solid lines), $\mathrm{CO}$ (dashed lines) vs $\lambda$ for different operating conditions: a) $d l=24 \mathrm{~mm}, T_{\text {air }}=703 \mathrm{~K}$; b) $0 \% \mathrm{H}_{2}, T_{\text {air }}=703 \mathrm{~K}$; c) $40 \% \mathrm{H}_{2}$, $T_{\text {air }}=703 \mathrm{~K}$; and d) vs adiabatic flame temperature (corresponding $\lambda$ for selected cases shown in brackets), $d l=24 \mathrm{~mm}, 0 \% \mathrm{H}_{2}$.

investigated system, the operating conditions with $v=90 \mathrm{~ms}^{-1}$ are not useful for application in GT engines. However, comparison of the results with different $\mathrm{H}_{2}$ content and at $v=160 \mathrm{~ms}^{-1}$, and with $d l=0 \mathrm{~mm}$ (nonpremixed), could provide information about the different influencing parameters in flameless mode of combustion.

Figure 4a shows the $\mathrm{NO}_{x}$ and $\mathrm{CO}$ concentrations vs $\lambda$ for changes in $v$ and $\mathrm{H}_{2}$ content. The four different routes in the formation of $\mathrm{NO}_{x}$ are thermal route (Zeldovich-NO), the prompt route (Fenimore-NO), the $\mathrm{N}_{2} \mathrm{O}$ route, and the fuel bound nitrogen $(\mathrm{FBN})$ route. Except FBN, depending on the operating condition, all of the other three routes could play an important role in $\mathrm{NO}_{x}$ formation in the current case. The key reactions for the three routes are [23]

$$
\begin{array}{cl}
\mathrm{O}+\mathrm{N}_{2} \leftrightarrow \mathrm{NO}+\mathrm{N} \quad(\text { Zeldovich }-\mathrm{NO}) \\
\mathrm{CH}+\mathrm{N} \leftrightarrow \mathrm{HCN}+\mathrm{N} \quad(\text { Fenimore }-\mathrm{NO})
\end{array}
$$

$$
\begin{gathered}
\mathrm{N}_{2}+\mathrm{O}+\mathrm{M} \leftrightarrow \mathrm{N}_{2} \mathrm{O}+\mathrm{M} \quad \mathrm{N}_{2} \mathrm{O}+\mathrm{O} \leftrightarrow \mathrm{NO}+\mathrm{NO} \\
\left(\mathrm{N}_{2} \mathrm{O}-\text { route }\right)
\end{gathered}
$$

Because of the high activation energy of reaction 3, the ZeldovichNO mechanism contributes to the total NO predominantly at high temperatures $(T>1700 \mathrm{~K})$. At lean conditions, the formation of $\mathrm{CH}$

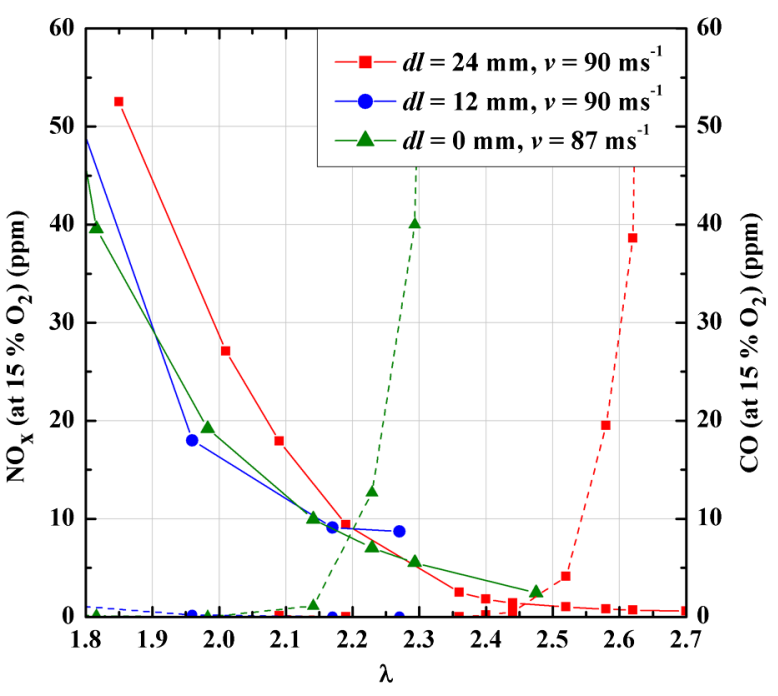

b)

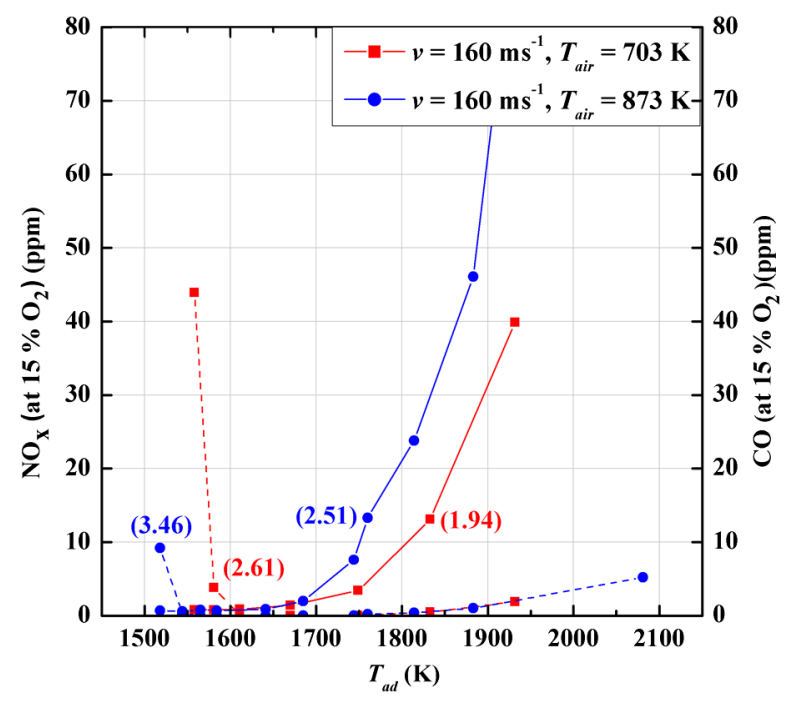

d)
ions: a) $d l=24 \mathrm{~mm}, T_{\text {air }}=703 \mathrm{~K}$; b) $0 \% \mathrm{H}_{2}, T_{\text {air }}=$
ected cases shown in brackets), $d l=24 \mathrm{~mm}, 0 \% \mathrm{H}_{2}$

is suppressed and hence leads to less Fenimore-NO. In the FC mode, especially in LEOR, an increased contribution to the total NO is via reaction 5. Moreover, this will be promoted at high pressures because of the three-body reaction and, typical for three-body reactions, has low activation energy. This was also found in earlier studies to be the major source of NO in lean premixed combustion in GT engines [24] and in the simulations of the current FLOX combustor tested with $\mathrm{NG}$ as fuel [25]. Also, at high mixing rates between the fresh reactants and the burned gases, the Fenimore-NO path can become more relevant, complementing the $\mathrm{N}_{2} \mathrm{O}$ route at higher mixing rates [26].

For a fixed $\lambda$ and $v$, the addition of $\mathrm{H}_{2}$ as an admixture to $\mathrm{NG}$ increases the global adiabatic temperature, thereby promoting the formation of $\mathrm{NO}_{x}$ via the Zeldovich mechanism, as seen in Fig. 4a. On the other hand, increasing the velocity from 90 to $160 \mathrm{~ms}^{-1}$ promotes mixing between the fresh fuel and the burned gases. With increased mixing, regions with $\lambda \ll \lambda_{\text {global }}$ are diminished and local temperature peaks are avoided. There is another effect that might contribute to a temperature reduction. A portion of the recirculated burned gas suffers a temperature loss due to wall contact leading to temperatures below the adiabatic temperature (note that, in GT engines, the heat transferred to the walls is not lost because it remains in the system). Both effects reduce the flame temperature, and thereby the $\mathrm{NO}_{x}$ emissions. This is because of the high activation energy of the thermal-NO mechanism, which thereby implies that 
any process that suppresses peak temperatures will result in a reduction in the $\mathrm{NO}_{x}$ emissions. In addition, the increased mixing also reduces the $\mathrm{CO}$ formation. Near the lean extinction limit, combustion tends to become incomplete due to kinetic effects that lead to an increase in CO concentration. An extension of the LEOR by increased mixing is thus favorable for a reduction in $\mathrm{CO}$ emissions. By increasing the velocity, the oxidation of $\mathrm{CO}$ is accelerated due to the increased circulation of burned gases $(\mathrm{OH})$. The increased recirculation also improves the flame stability as the mixing of the fresh gases with the hot burned gases increases the mixture temperature, and thereby the reactivity of the mixture. This suggests that the rise in $\mathrm{CO}$ emissions at $v=160 \mathrm{~ms}^{-1}$ above the $10 \mathrm{ppm}$ limit of LEOR will be at a higher $\lambda$ than at $v=90 \mathrm{~ms}^{-1}$. To sum up, this also implies that an increase in velocity in general will help in increasing the width of LEOR or the operational range of FC, as seen in Fig. 4a.

Changing the fuel nozzle from $d l=24 \mathrm{~mm}$ (premixed) to $d \bar{l}=$ $0 \mathrm{~mm}$ (nonpremixed) is seen to change the $\mathrm{NO}_{x}$ and $\mathrm{CO}$ values as well. While the $\mathrm{NO}_{x}$ reaches LEOR for approximately the same $\lambda$ value, the $\mathrm{CO}$ values increase above the $10 \mathrm{ppm}$ level at lower $\lambda$ values for $d l=0 \mathrm{~mm}$ than for $d l=24 \mathrm{~mm}$ (Fig. $4 \mathrm{~b}$ ). The interpretation of this result is not straightforward because the degree of premixing has an influence on local flame temperature and the location where the flame is ignited, which in turn determines the amount of burned gas mixed into the fuel/air mixture. From Figs. $4 \mathrm{a}$ and $\underline{4 c}$, it can be seen that an increase in $v$ leads to a shift of the $\mathrm{NO}_{x}$ curves toward lower values of $\lambda$ and broadening of the operating range for both the premixed and nonpremixed cases. At $v=90$ and $160 \mathrm{~ms}^{-1}$, and with $0 \% \mathrm{H}_{2}$ addition, the premixed mode has the advantage of a broader operating range (Fig. 4a) with respect to LEOR. But with $40 \% \mathrm{H}_{2}$ as an admixture (Fig. 4c), the broad operating range can be achieved only by increasing the nozzle exit velocities that, on the other hand, afford higher pressure losses at the burner. Although the $\mathrm{NO}_{x}$ and $\mathrm{CO}$ curves at low velocity follow the same trend for both $d l=0$ and $24 \mathrm{~mm}$, for the premixed mode, the lower $\mathrm{NO}_{x}$ and $\mathrm{CO}$ values are attained only at higher values of $\lambda$ (or lower $T_{\mathrm{ad}}$ ).

The influence of air preheating on the global emissions in a FC combustor is shown in Fig. $4 \mathrm{~d}$. In general, a consequence of high $T_{\text {air }}$ is increased temperature in the flame with an enormous effect on the thermal-NO formation. However, in the FC mode of combustion due to mixing of the fuel/air with the burned gases, the formation of temperature spikes in the heat release zone is avoided. For a fixed $\lambda$, increasing $T_{\text {air }}$ will lead to an increase in the global $T_{\text {ad }}$. For example, at $703 \mathrm{~K}$, the range of $\lambda$ at which the global $T_{\text {ad }}$ is between 1750 and $1900 \mathrm{~K}$ is from $2.13-1.75$, whereas at $873 \mathrm{~K}$, the range is approximately between 2.53 and 2.14. Also, from Fig. $4 \mathrm{~d}$ ( $\lambda$ corresponding to selected $T_{\mathrm{ad}}$ shown in brackets), it can be seen that an increase in $T_{\text {air }}$ from 703 to $873 \mathrm{~K}$ shifts the LEOR to higher $\lambda$ values, i.e., toward leaner mixtures. This implies that the FC mode of combustion opens up the possibility of operating the combustor at leaner conditions and higher $T_{\text {air }}$ without any substantial increase in the $\mathrm{NO}_{x}$ emissions.

To have a better understanding of the physical and chemical processes involved in the various trends seen in Fig. 4, the following sections concentrate further on the two-dimensional $\mathrm{OH}^{*}$ and $\mathrm{OH}$ PLIF measurements. Here, the reader is reminded that most of the $\mathrm{OH}-\mathrm{PLIF}$ and $\mathrm{OH}^{*}$ shown in the following sections are outside the LEOR. This is because of the low signal-to-noise $(\mathrm{S} / \mathrm{N})$ ratio of the images in LEOR leading to difficulties in interpretation of these images. In general, the OH-PLIF images in the LEOR had the lowest $\mathrm{S} / \mathrm{N}$ ratios. The single-shot OH-PLIF images in LEOR had a S/N ratio of approximately 2 for $0 \% \mathrm{H}_{2}$ content, with the $\mathrm{S} / \mathrm{N}$ ratios increasing with increasing $\mathrm{H}_{2}$ content ( $\mathrm{S} / \mathrm{N}$ of 5 for $40 \%$ ). However, the $\mathrm{OH}-\mathrm{PLIF}$ and $\mathrm{OH}^{*}$ images outside the LEOR region still provide valuable insight into the trends in the flame behavior with changes in the operational parameters.

\section{B. Influence of Hydrogen Admixture on Low Emissions Operating Range}

Figures $\underline{5}$ and $\underline{6}$ highlight the influence of the $\mathrm{H}_{2}$ admixture on LEOR. Here, the OH-PLIF measurement plane is near the combustion chamber windows, as shown in Fig. 2, intersecting the air nozzles at the top and bottom (the laser sheet travels from top to bottom), and the $\mathrm{OH}^{*}$ image is line-of-sight integrated. The vertical stripes seen in the OH-PLIF image in Fig. $\underline{5}$ are due to the blockage of part of the laser sheet in the combustor windows due to degradation of the quartz surface. The difference in LIF intensities between the upper and lower halves of the image is due to the absorption of the laser radiation by $\mathrm{OH}$ radicals. The $\mathrm{OH}-\mathrm{PLIF}$ images consist of three distinct regions: a dark region near the nozzle exit showing the cold inflow of fuel/air mixture where the temperature is less than $\sim 1400 \mathrm{~K}$, a high intensity region representing hot burned gas and regions of active combustion (especially in the case of $40 \% \mathrm{H}_{2}$, shown in Fig. 6), and a third region of moderate intensities representing relatively lower temperatures at the central and upstream regions between the nozzles (probably an outcome of the flow from the nozzle outside the laser sheet plane and heat loss at the burner plate, respectively). When compared with pure NG flames, the flames with $\mathrm{H}_{2}$ as an admixture have $\mathrm{OH}-\mathrm{LIF} / \mathrm{OH}^{*}$ intensities closer to the nozzle exit, highlighting the high reactivity of these mixtures. This can be seen in Fig. 5 and 6 for flames with 0 and $40 \%$ $\mathrm{H}_{2}$ content. Here, the reader is reminded that the range of the color bar is different. As the intensities of the $\mathrm{OH}-\mathrm{PLIF}$ and $\mathrm{OH}^{*}$ varied drastically for different operating conditions, each figure is displayed with an appropriate scaling factor to make the comparisons easier. For example, $8 \mathrm{x}$ means the signal intensity in the $\mathrm{OH}^{*}$ image shown is eight times stronger compared with images with $1 \mathrm{x}$. The $\mathrm{OH}^{*}$ chemiluminescence, which is a marker for the heat release zone, also shows dissimilar distribution for the different flames. The pure NG flame is evidently more distributed, with a more or less uniform spread of the $\mathrm{OH}^{*}$ intensities at $30-60 \mathrm{~mm}$ downstream. Here, the bright spots seen in the $\mathrm{OH}^{*}$ are from the impurities accumulated in the windows over time. The flame with $\mathrm{H}_{2}$ as the admixture has the heat release zone concentrated at a small region near the nozzle with relatively higher $\mathrm{OH}^{*}$ intensities. Although both flames have the same global $T_{\text {ad }}(1749 \mathrm{~K})$, the $\mathrm{NO}_{x} / \mathrm{CO}$ levels measured are $3.4 / 0.0 \mathrm{ppm}$ and $22.0 /<1 \mathrm{ppm}$ for 0 and $40 \% \mathrm{H}_{2}$, respectively, resulting in the $40 \% \mathrm{H}_{2}$ flame falling out of LEOR.

One of the reasons for this increase in the $\mathrm{NO}_{x}$ emission in the case of $40 \% \mathrm{H}_{2}$ admixture flame could be the smaller size of the
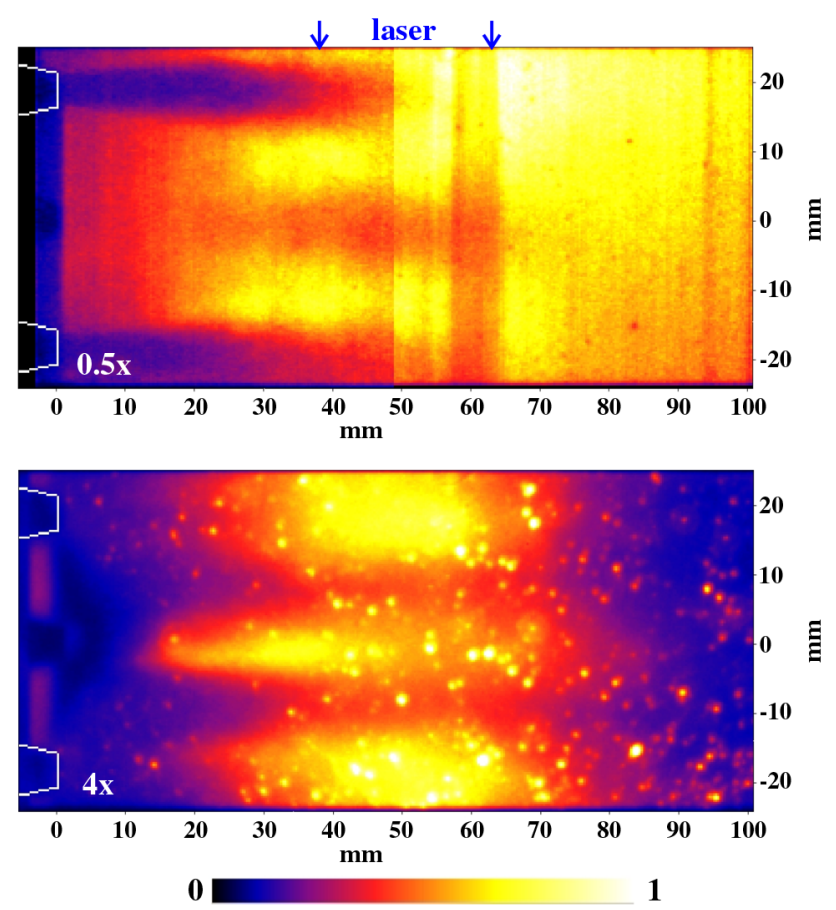

Fig. 5 Ensemble-averaged OH-PLIF (top) and $\mathrm{OH}^{*}$ (bottom) images for the operating point $d l=24 \mathrm{~mm}, v=160 \mathrm{~ms}^{-1}, 0 \% \mathrm{H}_{2}, \lambda=\mathbf{2 . 1 3}$, $T_{\text {ad }}=1749 \mathrm{~K}, \mathrm{NO}_{x} / \mathrm{CO}=3.4 / 0.0 \mathrm{ppm}$. Here, the OH-PLIF image covering the region of interest was created by merging the ensembleaveraged images measured at two axial locations. 

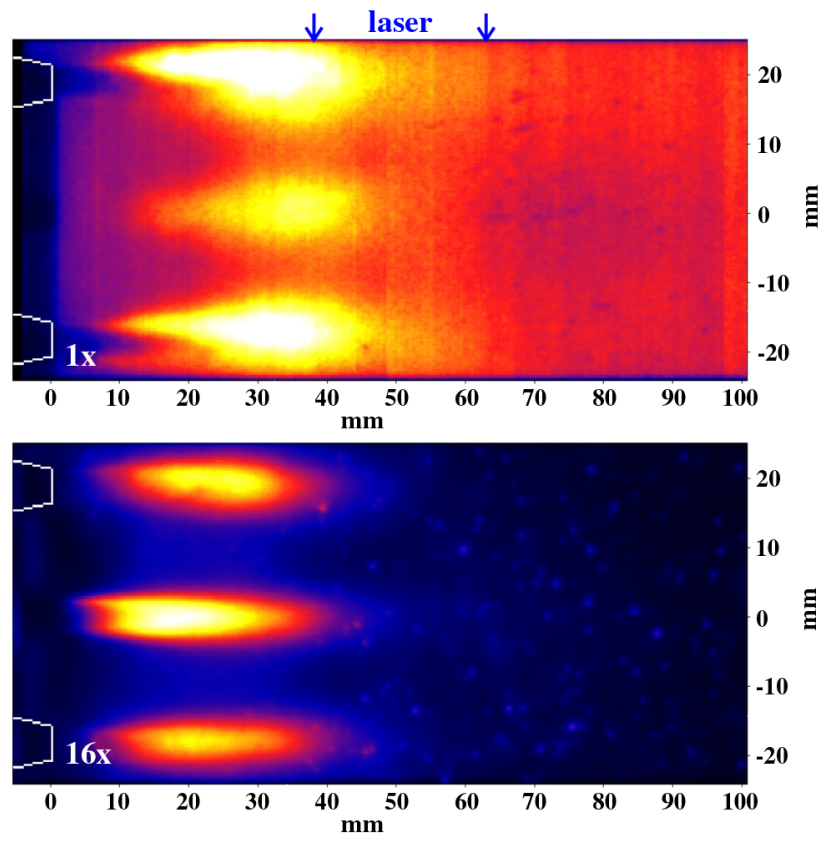

0

1

Fig. 6 Ensemble-averaged $\mathrm{OH}-\mathrm{PLIF}$ (top) and $\mathrm{OH}^{*}$ (bottom) images for the operating point $d l=24 \mathrm{~mm}, v=160 \mathrm{~ms}^{-1}, 40 \% \mathrm{H}_{2}, \lambda=\mathbf{2 . 1 9}$, $T_{\text {ad }}=1748 \mathrm{~K}, \mathrm{NO}_{x} / \mathrm{CO}=22.0 /<1 \mathrm{ppm}$.

combustion zone, as seen in $\mathrm{OH}^{*}$ distributions, with higher local temperature. In the single-shot OH-LIF images, the occurrences of these high-temperature pockets were visible for $40 \% \mathrm{H}_{2}$ mixtures. Figures $\underline{7}$ and $\underline{8}$ show randomly selected single-shot OH-PLIF images, the gradient of the OH-PLIF images, and the sum of gradients taken from 200 single-shot OH-PLIF images. The images shown in Figs. 7 and $\underline{8}$ are for 0 and $40 \% \mathrm{H}_{2}$ admixtures, respectively. Because of the asymmetry in laser-induced fluorescence (LIF) intensity caused by laser light absorption, only the upper halves of the images are taken for comparison. Sharp gradients in OH-PLIF images are indicative of reaction zones where large temperature gradients and superequilibrium $\mathrm{OH}$ concentrations are expected [2729]. Thus, the sum of gradients should provide an indication of the mean flame zone. The OH-PLIF and gradient images for $0 \% \mathrm{H}_{2}$ in Fig. 7 exhibit a diffuse distribution and look more like a distributed reaction zone, where the chemical timescale is much greater than the fluid dynamic timescale (Damköhler number, defined as the ratio of the fluid dynamic timescale to the chemical timescale, $D a<1$ ). However, the use of the gradient images for interpretation of such flames is questionable owing to the low $\mathrm{S} / \mathrm{N}$ ratio of the OH-PLIF images. Nevertheless, there are no indications of a well-defined reaction zone in these images. The flame with $40 \% \mathrm{H}_{2}$ admixture (Fig. 8) on the other hand shows indications of a flameletlike distribution $(D a>1)$ with localized high $\mathrm{OH}$ concentration zones. The sum of the gradients point to a region of sharp gradients at the outer shear layer between the fresh mixture and the recirculating burned gases for the $40 \% \mathrm{H}_{2}$ admixture, whereas no identifiable localized zones of sharp gradients were visible in the pure NG flame. This strengthens the earlier assumption that although the global $T_{\text {ad }}$ is the same for the two mixtures, the addition of $\mathrm{H}_{2}$ leads to the creation of localized high-temperature regions within the flowfield, which aids in the formation of $\mathrm{NO}_{x}$ through thermal-NO mechanism.

Another influencing factor on $\mathrm{NO}_{x}$ formation could be the role played by superequilibrium $\mathrm{O}$ atoms in the case of lean premixed flames at high pressures. Under such conditions, it was reported that both the Zeldovich and $\mathrm{N}_{2} \mathrm{O}$ mechanisms are enhanced by superequilibrium $\mathrm{O}$-atom concentration at the flame front [30]. Since one would expect partial equilibrium between $[\mathrm{O}]$ and $[\overline{\mathrm{OH}}]$ (i.e., $\left.[\mathrm{O}] /[\mathrm{O}]_{\text {Equil. }}=\left([\mathrm{OH}] /[\mathrm{OH}]_{\text {Equil. }}\right)^{2}\right)$, an $\mathrm{OH}$ concentration larger than equilibrium implies a significant increase of $\mathrm{O}$-atom concentrations above equilibrium. Although the existence of superequilibrium $\mathrm{O}$ atoms under the current experimental condition is not proven, its possible impact on the $\mathrm{NO}_{x}$ formation cannot be overlooked.

Here, one question that arises in the preceding discussions is the existence of a so-called distributed reaction zone regime. In the review paper from Driscoll [31], he commented that although there is experimental evidence of distributed combustion in rapid compression devices like HCCI, there is no proof to date that shows the existence of distributed reaction zones created by rapid turbulent mixing. In the current case, the OH-PLIF images alone under FC conditions are also rather poor candidates to state anything conclusive about distributed combustion owing to their very low $\mathrm{S} / \mathrm{N}$ ratios. However, previous investigations using simultaneous OH-PLIF and Rayleigh measurements under MILD [32] and FLOX [7] conditions showed no temperature gradients representative of a flameletlike regime in the region of heat release. Moreover, the fact that in the region of LEOR, the $\mathrm{NO}_{x}$ and $\mathrm{CO}$ (formed basically in the
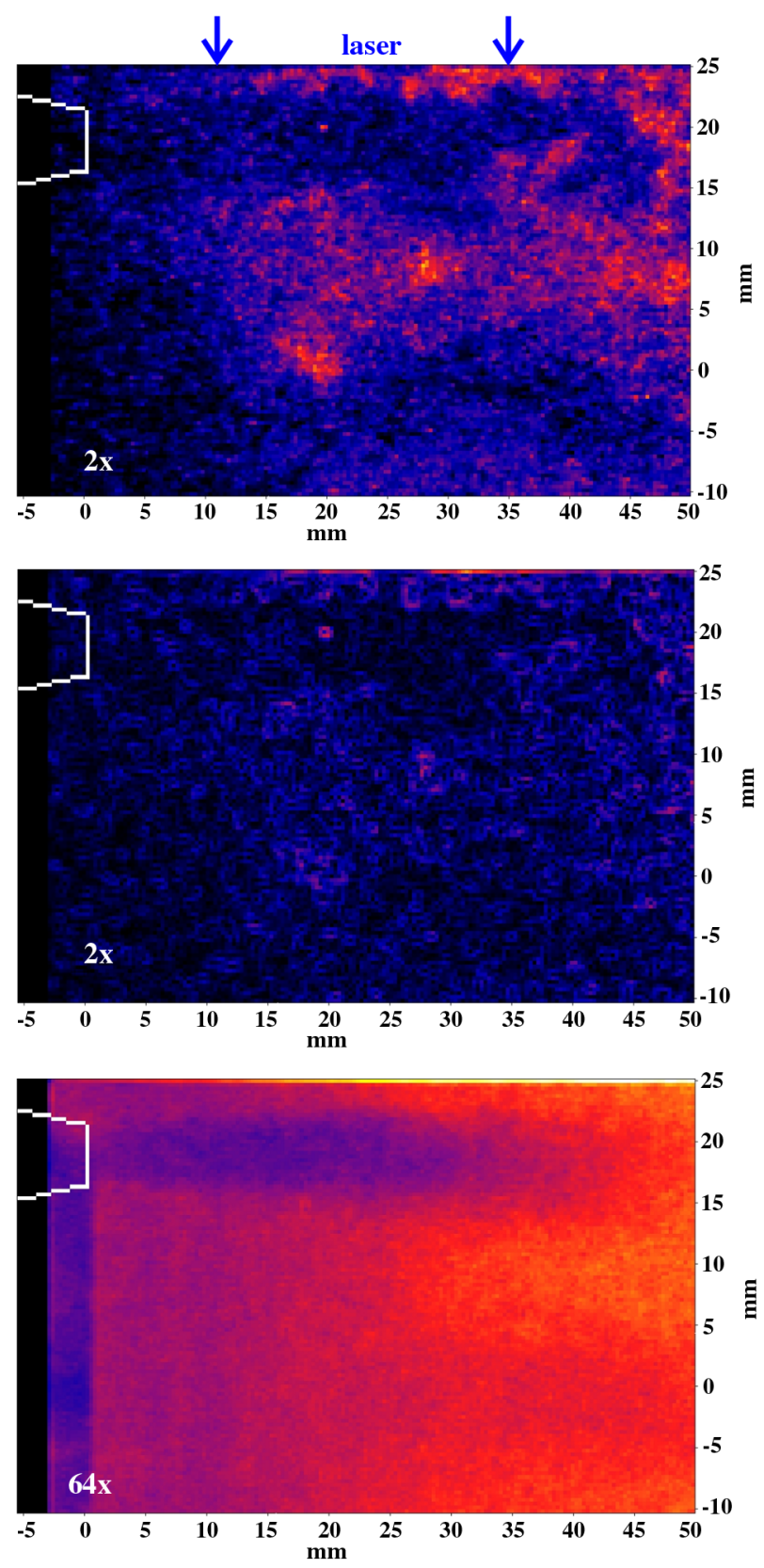

0

Fig. 7 Instantaneous OH-PLIF (top), gradient (middle), and sum of gradients (bottom) for the ensemble-averaged OH-PLIF shown in Fig. $5\left(d l=24 \mathrm{~mm}, v=160 \mathrm{~ms}^{-1}, 0 \% \mathrm{H}_{2}, \lambda=2.13, T_{\text {ad }}=1749 \mathrm{~K}\right.$, $\left.\mathrm{NO}_{x} / \mathrm{CO}=3.4 /<1 \mathrm{ppm}\right)$. 

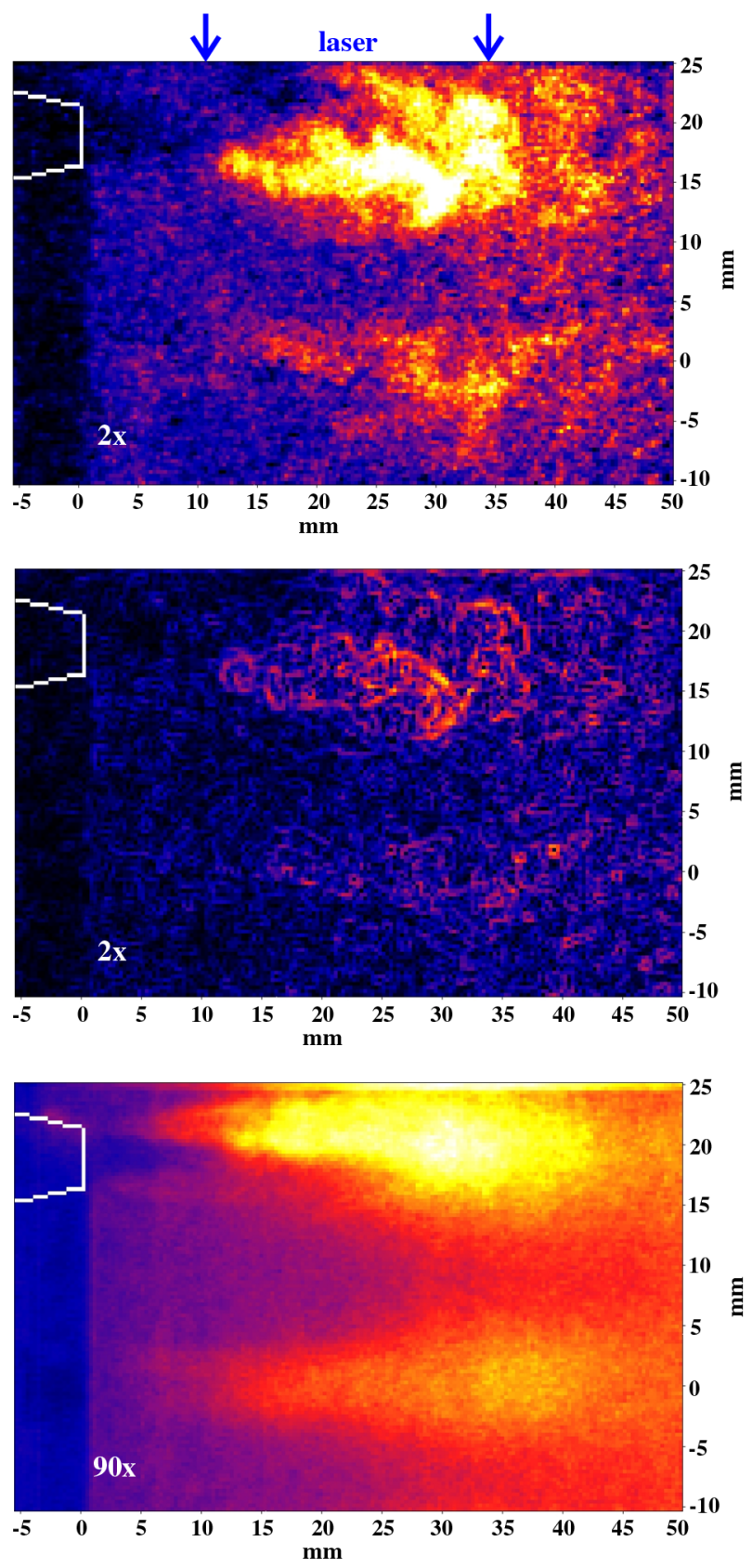

0

1

Fig. 8 Instantaneous OH-PLIF (top), gradient (middle), and sum of gradients (bottom) for the ensemble-averaged OH-PLIF shown in Fig. 6 $\left(d l=24 \mathrm{~mm}, \quad v=160 \mathrm{~ms}^{-1}, \quad 40 \% \quad \mathrm{H}_{2}, \quad \lambda=2.19, \quad T_{\text {ad }}=1748 \mathrm{~K}\right.$, $\left.\mathrm{NO}_{x} / \mathrm{CO}=22.0 /<1 \mathrm{ppm}\right)$.

high-temperature combustion zone) emissions are close to zero show that the possibility of having a flameletlike structure is rather unlikely, and combustion could be more distributed in nature. That being said, without any foolproof data (images of radicals characteristic of the heat release region like $\mathrm{CH}$ ), the existence of distributed combustion under FC conditions will remain an open question.

\section{Influence of $d l$ on Low Emissions Operating Range: Determining Premixed or Nonpremixed}

Most of the current low $\mathrm{NO}_{x}$ GT combustors operate at lean conditions where the $\mathrm{O}_{2}$ concentration in the combustor is high. However, creating a stable flame over a large operating range in a premixed mode is difficult, as the premixed combustion systems are highly dependent on the flame velocity of the mixture. The flame stability will be affected by the reactant dilution with burned gases.
The nonpremixed flames, on the other hand, although less sensitive to combustion air composition with regard to flame stability, are always affected by high $\mathrm{NO}_{x}$ emissions. But this is not necessarily the case under FC. For example, for the operating conditions shown in Figs. 9 and $10(\lambda=1.85)$ with fuel/air premixing $(d l=24 \mathrm{~mm})$ and nonpremixed $(d l=0 \mathrm{~mm})$, the $\mathrm{NO}_{x}$ values are relatively low (52.5 and $31.3 \mathrm{ppm}$, respectively). The figures show ensembleaveraged $\mathrm{OH}-\mathrm{PLIF}$ and $\mathrm{OH}^{*}$ images for cases with fuel/air premixing $\left(v=90 \mathrm{~ms}^{-1}\right)$ and nonpremixed $\left(v=98 \mathrm{~ms}^{-1}\right)$. By changing from premixed to nonpremixed modes, the spatial location of the heat release zone is seen to shift downstream; that is, there is an increase in the ignition delay time of the mixture. This is due to an increase in the chemical induction time (buildup of the radical pool) owing to the mixing process of fuel, air, and burned gases. Obviously, the premixed configuration generates autoigniting mixtures more rapidly than the nonpremixed one. Also recognizable is a decrease in the $\mathrm{OH}-\mathrm{PLIF}$ and $\mathrm{OH}^{*}$ intensities for the nonpremixed case, suggesting a decrease in the mixture temperature that, in turn, will have an impact on the $\mathrm{NO}_{x}$ emission values as well. This extended ignition distance for the nonpremixed configuration helps in reducing the local temperature (and the $\mathrm{NO}_{x}$ values) as it aids the mixing of the fresh gases with the recirculating gases before reaching the reaction zone.

At this stage, it will be interesting to have a close look at the combustion process in a single nozzle for both premixed and nonpremixed configurations. Figure 11 shows the $\mathrm{OH}^{*}$ and corresponding Abel inverted $\mathrm{OH}^{*}$ image for $d l=24 \mathrm{~mm}\left(v=160 \mathrm{~ms}^{-1}\right)$ and $d l=0 \mathrm{~mm}\left(v=127 \mathrm{~ms}^{-1}\right)$ with $40 \% \mathrm{H}_{2}$ admixture. In the case of axisymmetric flames, the line-of-sight integrated $\mathrm{OH}^{*}$ images can be Abel inverted to give spatially resolved information along the radial plane section. The main heat release zones in the case of $d l=24 \mathrm{~mm}$ are located at the shear layer between the fresh gases and the burned gases, with the two roots of the heat release zone
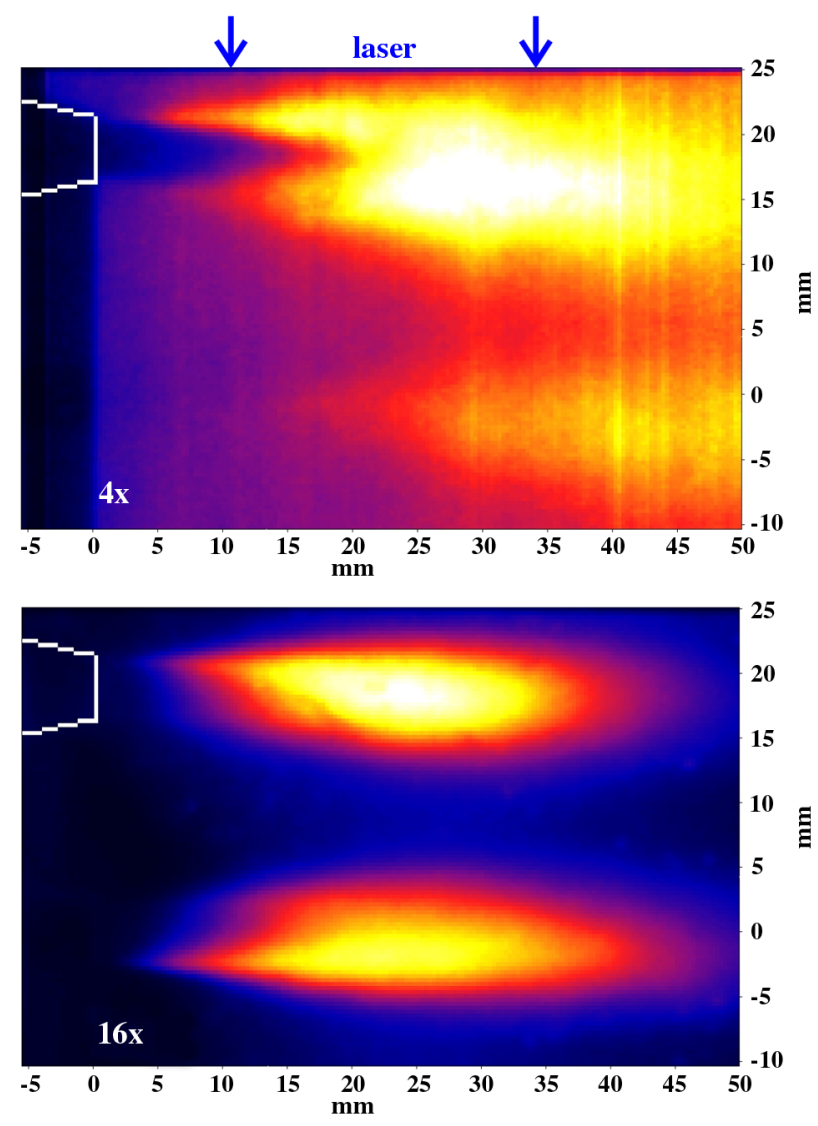

0

Fig. 9 Ensemble-averaged OH-PLIF (top) and OH* (bottom) images for the operating point $d l=24 \mathrm{~mm}, v=90 \mathrm{~ms}^{-1}, 0 \% \mathrm{H}_{2}, \lambda=1.85$, $T_{\text {ad }}=1874 \mathrm{~K}, \mathrm{NO}_{x} / \mathrm{CO}=52.5 /<1 \mathrm{ppm}$. 

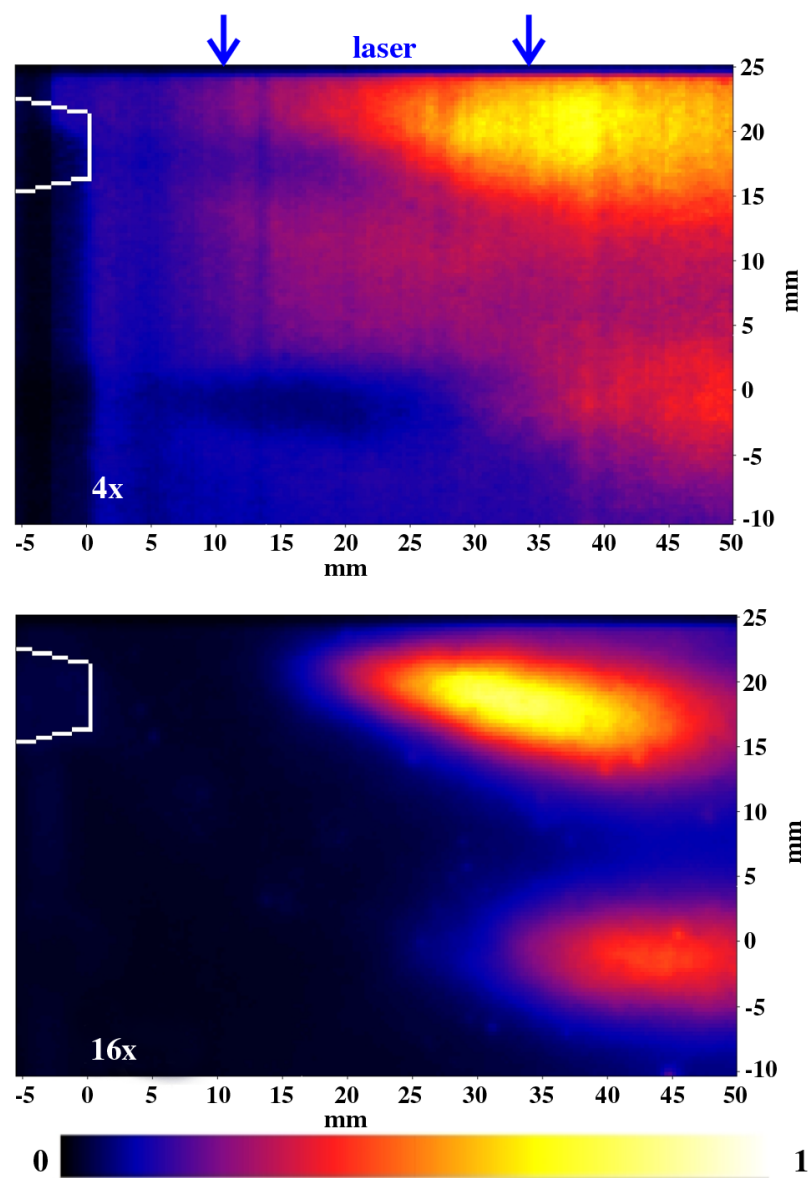

Fig. 10 Ensemble-averaged OH-PLIF (top) and $\mathrm{OH}^{*}$ (bottom) images for the operating point $d l=0 \mathrm{~mm}, v=98 \mathrm{~ms}^{-1}, 0 \% \mathrm{H}_{2}, \lambda=1.85$, $T_{\text {ad }}=1877 \mathrm{~K}, \mathrm{NO}_{x} / \mathrm{CO}=31.3 /<1 \mathrm{ppm}$.

starting approximately $3-5 \mathrm{~mm}$ from the nozzle exit. This result shows that fuel and air are so well premixed that they can be ignited by the burned gas close to the nozzle. This is not really desired for the FC mode because a significant dilution of the fresh gas by burned gases was not achieved; therefore, the influence of burned gas recirculation in the combustion process before the reaction zone is limited. Although the fuel/air premixing helps for reducing temperature peaks, the full potential of FC could not be exploited. On the other hand, for $d l=0 \mathrm{~mm}$, although the jet velocity is less, the heat release zone is established further downstream. The delayed ignition is most likely caused by the poor mixing, i.e., the shielding of the fuel stream by the airstream. This favors an effective dilution of the fresh fuel/air mixture by the burned gases.

The preceding results support the definition from [6] that, in order to have a FC combustion mode, the burned gas recirculation process has to occur in the combustor before the reaction zone (only burned gas recirculated into combustion air and fuel before the reaction zone is considered to be recirculated burned gas [6] ]). With enough recirculation, mixtures with temperatures higher than the autoignition temperature are created, thereby producing the stabilizing effect of excess enthalpy combustion together with reduced combustion temperatures [33]. Here, the combustion temperature decreases with dilution as the burned gases are at lower temperatures than the adiabatic flame temperature (due to the nonadiabatic nature of the combustor), resulting in dilution having a cooling effect on the flame locally. The local temperature peaks are reduced, and the homogeneity of the temperature distribution is improved.

\section{Effect of Increase in Jet Velocity on Low Emissions Operating Range}

It was seen from the $\mathrm{NO}_{x} / \mathrm{CO}$ vs $\lambda$ plots in Fig. $\underline{4}$ that the increase in velocity increases the width of LEOR as it aids in reducing the $\mathrm{NO}_{x}$ values drastically, irrespective of whether the mixture is premixed or nonpremixed. For example, consider the following two premixed, pure NG flames at velocities $v=90 \mathrm{~ms}^{-1}\left(\lambda=1.85, T_{\text {ad }}=1874 \mathrm{~K}\right.$, $\left.\mathrm{NO}_{x} / \mathrm{CO}=52.5 /<1 \mathrm{ppm}\right)$ and $v=160 \mathrm{~ms}^{-1}\left(\lambda=1.75, T_{\mathrm{ad}}=\right.$ $\left.1932 \mathrm{~K}, \mathrm{NO}_{x} / \mathrm{CO}=39.9 / 1.9 \mathrm{ppm}\right)$. The ensemble-averaged $\mathrm{OH}-$ PLIF and $\mathrm{OH}^{*}$ images are shown in Figs. 9 and 12, respectively. The position and shape of the $\mathrm{OH}^{*}$ images look quite similar for both cases in the averaged image. However, the $\mathrm{NO}_{x}$ values for $v=$ $160 \mathrm{~ms}^{-1}$ are lower than that for $v=90 \mathrm{~ms}^{-1}$ in spite of having a higher global $T_{\text {ad }}$. This highlights the interplay between $\lambda$ or $T_{\text {ad }}$ and $v$, and neither one of them alone can provide conclusive prediction about the flame behavior or the emission characteristics. The singleshot LIF images (see Fig. 13) at $90 \mathrm{~ms}^{-1}$ show frequent occurrence of localized high $\mathrm{OH}$ intensity (or high temperature) zones, whereas the LIF at $160 \mathrm{~ms}^{-1}$ was more distributed in nature with low $\mathrm{OH}$ intensities. Moreover, high rms fluctuations in OH-PLIF intensity result from the intermittent nature of the reaction zone. So, its spatial distribution can be taken as an indicator for the reaction zone location, which in this case also looks quite similar. Also, the flame with $v=90 \mathrm{~ms}^{-1}$ seems to be ignited closer to the nozzle. As mentioned earlier, $\mathrm{OH}^{*}$ chemiluminescence is mainly associated with the reaction zone. But $\mathrm{OH}$ radicals exist in abundance in both reaction zones and at high-temperature regions, like the burned gases where the temperature of the gases is approximately above $1400 \mathrm{~K}$. The OH-LIF intensity can be taken as a measure of the relative temperature distribution. Therefore, the very low OH-LIF intensity in the single shots and averaged images at $v=160 \mathrm{~ms}^{-1}$ at regions close to the burner and in the recirculation region point to a mixture at relatively lower temperatures. So, although there is a significant heat release at regions close to the nozzle exit for both the flames, the high recirculation rates as a result of the increase in the jet velocity promote efficient mixing of the high-temperature gases from the reaction zone with a relatively low temperature recirculating burned gases leading to an overall decrease in the global temperature. This reduction in temperature is an important step for $\mathrm{NO}_{x}$ reduction as, according to the Zeldovich-NO mechanism, even a short residence
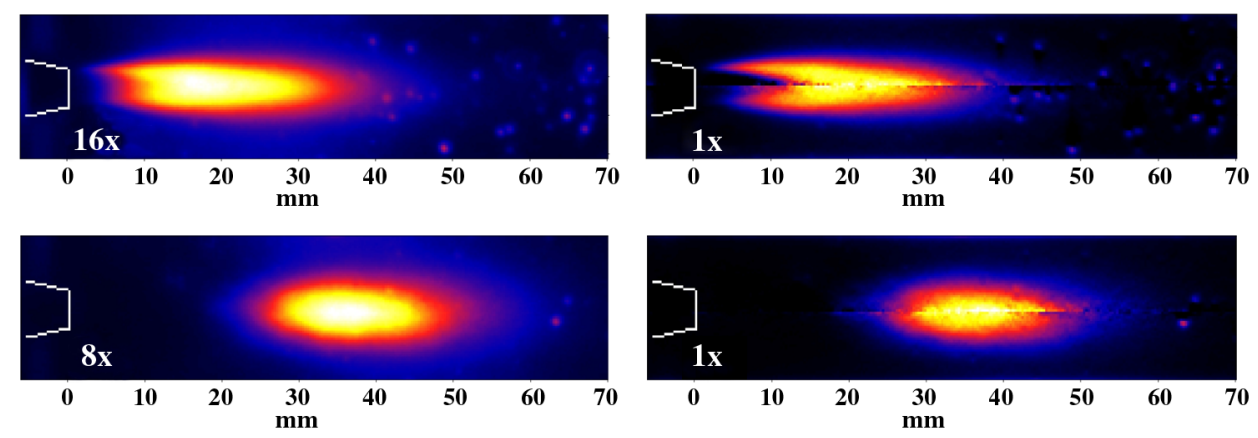

Fig. 11 Ensemble-averaged $\mathrm{OH}^{*}$ (left) and its Abel deconvolution (right) for the operating points $d l=24 \mathrm{~mm} v=160 \mathrm{~ms}^{-1}, 40 \% \mathrm{H}_{2}, \lambda=2.20$, $T_{\text {ad }}=1743 \mathrm{~K}, \mathrm{NO}_{x} / \mathrm{CO}=20.1 / 0 \mathrm{ppm}\left(\right.$ top); and $d l=0 \mathrm{~mm}, v=127 \mathrm{~ms}^{-1}, 40 \% \mathrm{H}_{2}, \lambda=2.23, T_{\text {ad }}=1731 \mathrm{~K}, \mathrm{NO}_{x} / \mathrm{CO}=19.6 / 0 \mathrm{ppm}(\mathrm{bottom})$. 

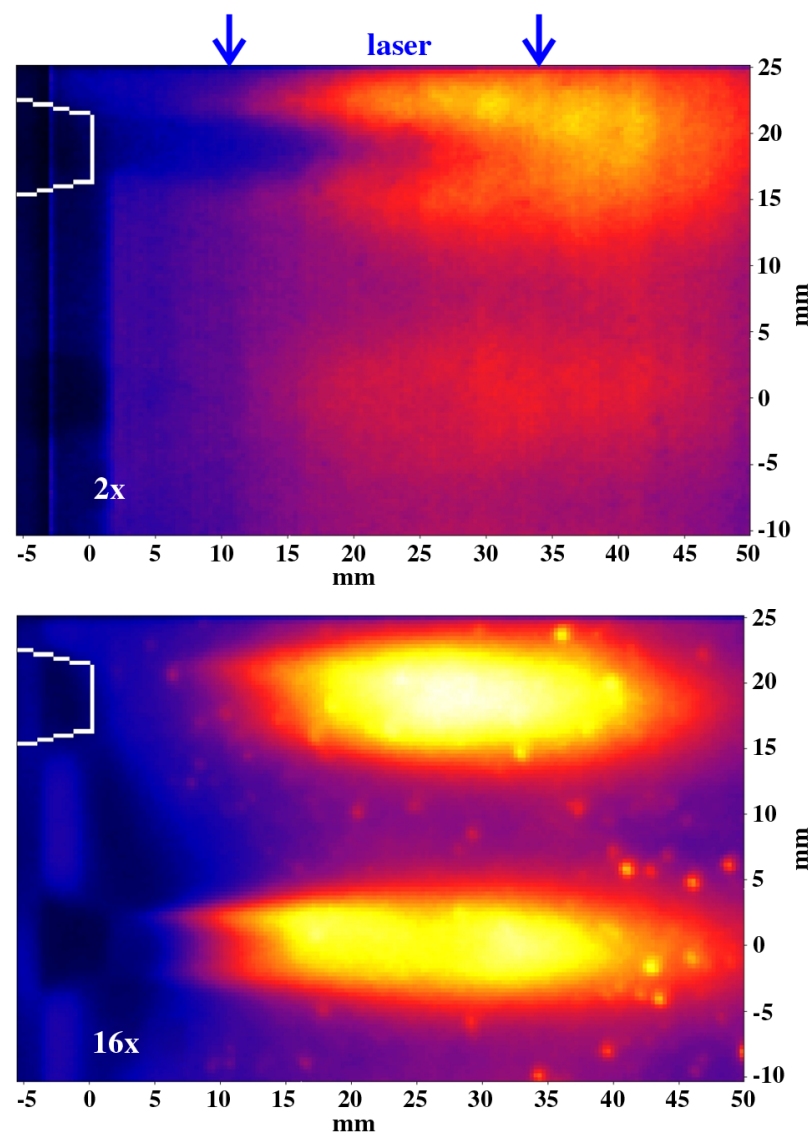

0 1

Fig. 12 Ensemble-averaged OH-PLIF (top) and $\mathrm{OH}^{*}$ (bottom) images for the operating point $d l=24 \mathrm{~mm}, 0 \% \mathrm{H}_{2}, v=160 \mathrm{~ms}^{-1}, \lambda=1.75$, $T_{\text {ad }}=1932 \mathrm{~K}, \mathrm{NO}_{x} / \mathrm{CO}=39.9 / 1.9 \mathrm{ppm}$.
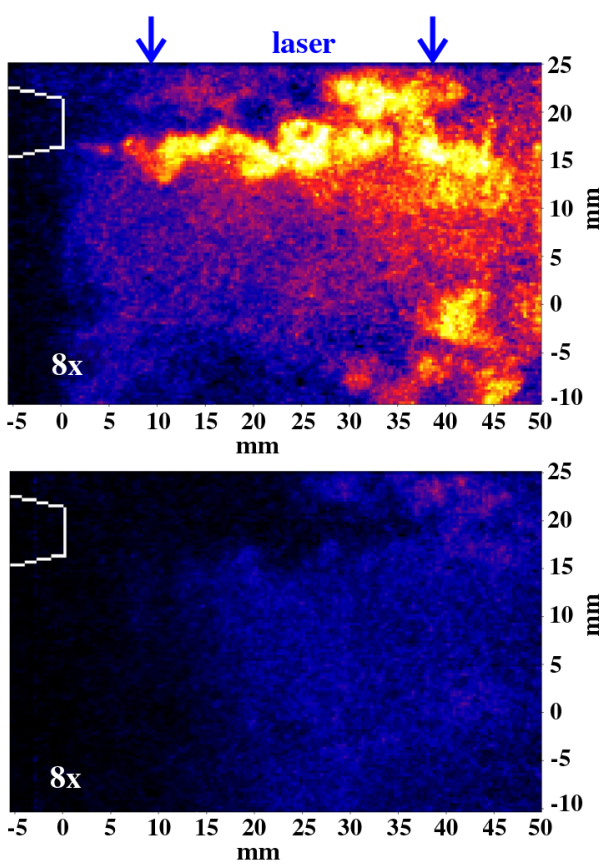

0 time at high temperature can lead to a significant NO formation [34]. From Eq. (3), the kinetic rate law can be written as [23]

$$
\frac{\mathrm{d}[\mathrm{NO}]}{\mathrm{d} t}=2 k[\mathrm{O}]\left[\mathrm{N}_{2}\right]
$$

For a given temperature and pressure, $k$ and $\mathrm{N}_{2}$ concentrations do not vary much. So the $\mathrm{NO}_{x}$ formation depends mainly on the time $t$ and [O] atoms. By maintaining shorter residence time at high temperatures through fast burned gas recirculation, the thermal-NO formation is largely reduced. Thus, for optimum combustion, the combustor should provide appropriate residence time so that it is long enough to completely oxidize $\mathrm{CO}$ to $\mathrm{CO}_{2}$ but short enough to avoid the $\mathrm{NO}_{x}$ formation by thermal process [33].

Even in the case of $\mathrm{NG}$ flames with $\mathrm{H}_{2}$ admixture, these mixing effects are clearly visible. For example, Fig. 14 shows a randomly selected instantaneous OH-PLIF image, the corresponding gradient image, and the summation of gradients from 200 instantaneous images for a flame with $40 \% \mathrm{H}_{2}$ admixture and $v=90 \mathrm{~ms}^{-1}$. In comparing the sum of gradients shown in Fig. $\underline{8}$ with Fig. 14, it can be seen that the locations of the flame zones are quite similar for both 90 and $160 \mathrm{~ms}^{-1}$, but the flame with $90 \mathrm{~ms}^{-1}$ is ignited a little bit closer to the nozzle. This can be explained by the longer residence time at lower velocities and the smaller strain rates in the shear layer. Although the global $T_{\text {ad }}$ for the $160 \mathrm{~ms}^{-1}$ mixture $(1748 \mathrm{~K})$ is slightly higher than that for $90 \mathrm{~ms}^{-1}(1722 \mathrm{~K})$, the $\mathrm{NO}_{x}$ is $50 \%$ less. These examples clearly show a drastic decrease in $\mathrm{NO}_{x}$ values (or increase in width of LEOR) achieved with increasing jet velocities, as seen in Fig. 4a. The reduction of $\mathrm{NO}_{x}$ formation can be explained by the smaller contribution of the Zeldovich-NO route, because at higher jet velocities, the residence time in high-temperature regions decreases. Furthermore, the mixing rate increases with increasing velocity so that flame temperatures are reduced by the admixtures of recirculated burned gas that suffered a temperature loss due to wall contact.

At this point, it is to be stressed that the mechanism responsible for $\mathrm{NO}_{x}$ reduction with increasing jet velocities in the case of $d l=$ $24 \mathrm{~mm}$ (premixed) depends on the mixture composition also. In the case of richer mixtures where the flame is stabilized closer to the nozzle exit, the effect of burned gas dilution of the fresh fuel/air with increasing jet velocities before combustion will be limited. However, a fast mixing also contributes to $\mathrm{NO}_{x}$ reduction in this case because
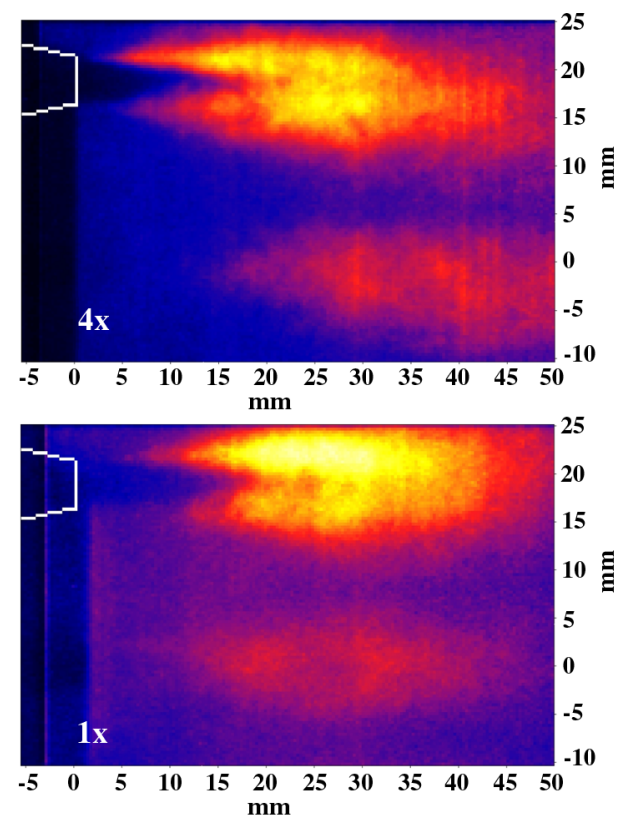

\section{1}

Fig. 13 Single-shot OH-PLIF (left) and rms fluctuations (right) corresponding to the flames shown in Fig. 9 (top: $d l=24 \mathrm{~mm}, v=90 \mathrm{~ms} \mathrm{~s}^{-1}, 0 \% \mathrm{H}_{2}$, $\lambda=1.85, T_{\mathrm{ad}}=1874 \mathrm{~K}, \mathrm{NO}_{x} / \mathrm{CO}=52.5 /<1 \mathrm{ppm}$ ) and Fig. $\underline{12}$ (bottom: $d l=24 \mathrm{~mm}, 0 \% \mathrm{H}_{2}, \bar{v}=160 \mathrm{~ms}^{-1}, \lambda=1.75, T_{\mathrm{ad}}=1932 \mathrm{~K}$, $\left.\mathrm{NO}_{x} / \mathrm{CO}=39.9 / 1.9 \mathrm{ppm}\right)$. 
the temperature of the freshly reacted gas is reduced by mixing with recirculated burned gas. But, in the case of moderately lean mixtures due to the increased ignition delay times, the flame is stabilized further downstream from the nozzle exit. An increase in mixing rate with increasing jet velocities will lead to enhanced mixing of the fuel/ air mixture with the recirculating burned gases long before the reaction is initiated. This favors the formation of a distributed region of combustion with a suppression of the local temperature peaks and gradients, as explained in the previous section. So here, the $\mathrm{NO}_{x}$ reduction is achieved not only by cooling of the high-temperature burned gases after the reaction zone but also by improving the homogeneity of the temperature distribution. In the case of very lean mixtures (FC mode), the $\mathrm{NO}_{x}$ reduction is mainly a result of burned gas dilution of the reactants.

From Fig. $4 \mathrm{~b}$, it was seen that LEOR can be shifted to lower $\lambda$ (richer conditions) by changing the air nozzle geometry from premixed to nonpremixed. Also, discussions in Sec. III.C have
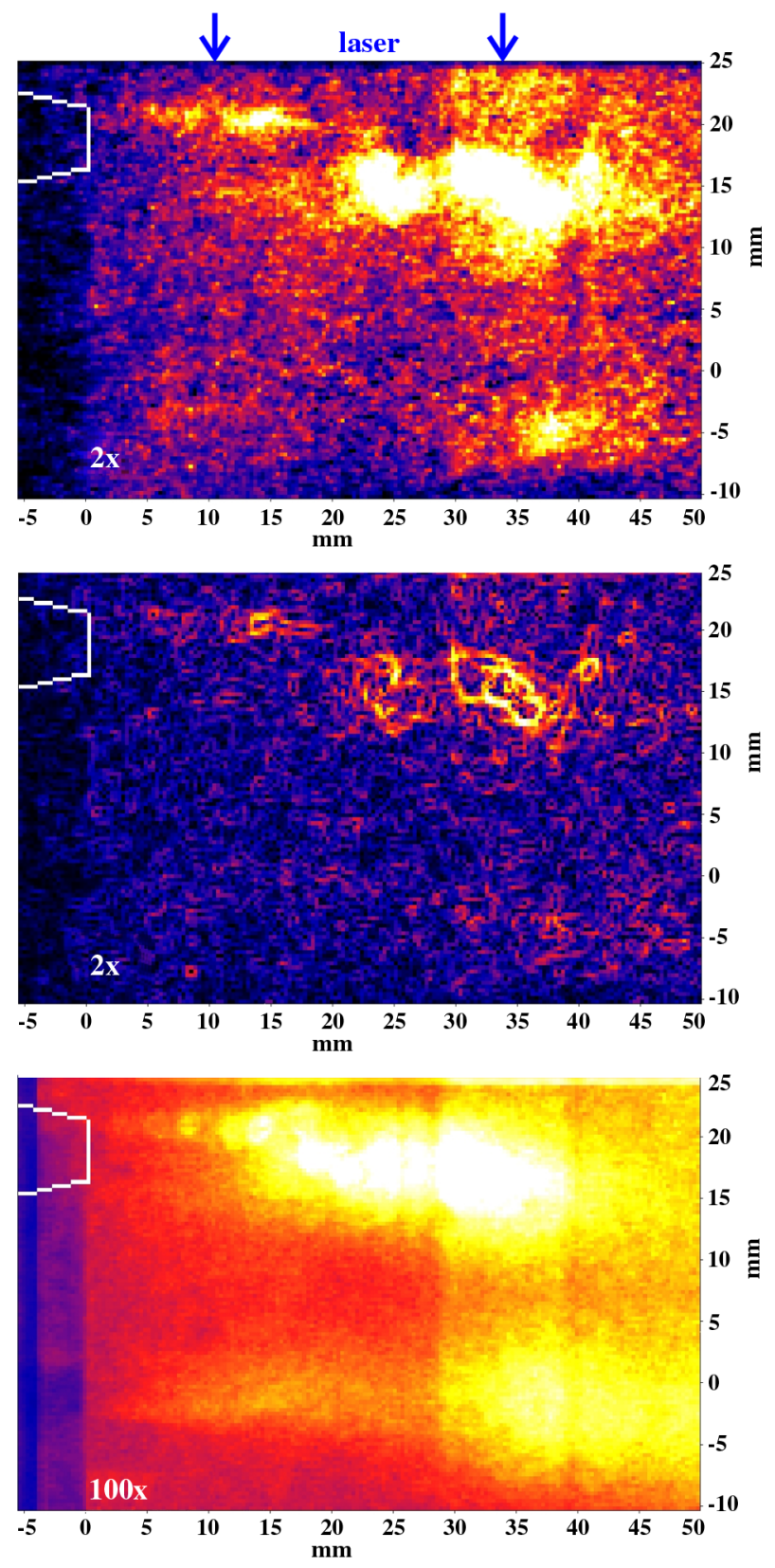

0

Fig. 14 Instantaneous OH-PLIF (top), gradient (middle), and sum of gradients (bottom) for the operating point $d l=24 \mathrm{~mm}, 40 \% \mathrm{H}_{2}$, $v=90 \mathrm{~ms}^{-1}, \lambda=2.26, T_{\text {ad }}=1722 \mathrm{~K}, \mathrm{NO}_{x} / \mathrm{CO}=48.1 /<1 \mathrm{ppm}$. shown that for the same $\lambda$ (or $T_{\mathrm{ad}}$ ), lower emission values were achieved under nonpremixed conditions as ignition was delayed until enough exhaust was mixed, thereby avoiding peak temperatures. However, from the discussion in the current section, it became obvious that the jet velocity had an important influence on mixing, flame stabilization, and $\mathrm{NO}_{x}$ formation. Increased recirculation and mixing rates reduce peak temperature and residence time in hightemperature zones. It was also seen that at high jet velocities, the premixed flames burned stably over a wider operating range than the nonpremixed case (Fig. $\underline{4 c}$ ).

\section{Conclusions}

The application of the FC combustion mode at high pressures and temperatures with $\mathrm{H}_{2}$ as an admixture to NG fuels was demonstrated in this research study. The FLOX burner was equipped with an optically accessible combustion chamber for the optical and laser diagnostic measurements and was operated with preheated air at a pressure of 20 bar. The goal was to investigate the influence of different competing parameters like combustor inlet velocities, percentage of $\mathrm{H}_{2}$ admixture, air equivalence ratios, and extent of premixing on the flame shape and pollutant emissions in the FC mode of combustion.

The flame with $\mathrm{H}_{2}$ as an admixture burned closer to the burner when compared with pure NG flames owing to the high reactivity of $\mathrm{H}_{2}$. But, the high flame temperatures of such flames had a large effect on the $\mathrm{NO}_{x}$ formation by enhancing both thermal-NO and $\mathrm{N}_{2} \mathrm{O}$ mechanisms. The investigations showed that for a fixed $\lambda$, the recirculation rate of the burned gases plays a vital role in the emission levels. Since the recirculation rate is directly coupled with the jet exit velocities, an increase in jet velocities was seen to increase the width of LEOR. In principle, it is possible to achieve LEOR, irrespective of the extent of premixing in the fuel/air nozzle, but the mechanisms differ. The OH-PLIF and $\mathrm{OH}^{*}$ images showed that the heat release zones were shifted further downstream with a decrease in the level of premixing as a result of the shielding of the fuel by the airstream. This delay in flame ignition is important for achieving LEOR, as it provides enough time for burned gas dilution of the unburned gases that, in turn, will reduce the local temperature peaks and improve the homogeneity of the temperature distribution. In this regard, the purely premixed mode was disadvantageous, as it led to an early ignition of the flame closer to the nozzle. On the other hand, the purely nonpremixed configuration, although it promoted burned gas recirculation into combustion air and fuel before the reaction zone, was seen to suffer from a narrow LEOR.

Comparable emission levels between the premixed and nonpremixed mode can be achieved by increasing the mixing rate in the former mode by applying higher jet velocities. However, this requires a higher pressure loss at the nozzle, and thus means a reduction in overall efficiency of the system. Irrespective of the premixed or nonpremixed configurations, increasing the jet velocities leads to mainly three effects:

1) It promotes the mixing between the fresh fuel/air and the recirculating burned gases.

2) It accelerates the temperature decline of the high-temperature burned gases at the flame front by promoting mixing with the relatively colder recirculating burned gases.

3) It shortens the flame residence time.

The current studies showed that in order to achieve an optimum operating range with low emissions for a specific combination of degree of premixing and jet velocities, the recirculation rate should be such that the ignition delay is short enough to enable a reliable flame stabilization but long enough for burned gas dilution of the fresh fuel/air mixture before the reaction zone. At the same time, the combustor residence times should be short in order to suppress Zeldovich-NO formation but long enough to oxidize $\mathrm{CO}$ to $\mathrm{CO}_{2}$.

\section{Acknowledgments}

The work was supported by the German Federal Ministry for Economy and Labour (BMWi) as per resolution of the German 
Federal Parliament under grant number 0327710L. The investigations were conducted as part of the joint research program $\mathrm{CO} 2-$ Reduktion durch Effizienz-Turbo in the frame of AG Turbo. The authors gratefully acknowledge AG Turbo for their support and permission to publish this paper. The responsibility for the content lies solely with its authors. The authors would also like to acknowledge the support of U. Prestel and K. H. Ferst.

\section{References}

[1] Røkke, P. E., and Hustad, J. E., "Exhaust Gas Recirculation in Gas Turbines for Reduction of CO2 Emissions; Combustion Testing with Focus on Stability and Emissions", International Journal of Thermodynamics, Vol. 8, No. 4, 2005, pp. 167-173.

[2] Li, H., ElKady, A. M., and Evulet, A. T., "Effect of Exhaust Gas Recirculation on NOx Formation in Premixed Combustion System," 47th AIAA Aerospace Sciences Meeting, Orlando, FL, AIAA Paper 2009-226, 2009.

[3] Katsuki, M., and Hasegawa, T., "The Science and Technology of Combustion in Highly Preheated Air," Proceedings of the Combustion Institute, Vol. 27, No. 2, 1998, pp. 3135-3146. doi:10.1016/S0082-0784(98)80176-8

[4] Bobba, M. K., Gopalakrishnan, P., Periagaram, K., and Seitzman, J. M., "Flame Structure and Stabilization Mechanisms in a Stagnation-Point Reverse-Flow Combustor," Journal of Engineering for Gas Turbines and Power, Vol. 130, No. 3, 2008, Paper 031505 doi:10.1115/1.2836614

[5] Cavliere, A., and de Joannon, M., "Mild Combustion," Progress in Energy and Combustion Science, Vol. 30, 2004, pp. 329-366. doi:10.1016/j.pecs.2004.02.003

[6] Wünning, J. A., and Wünning, J. G., "Flameless Oxidation to Reduce Thermal NO-Formation," Progress in Energy and Combustion Science, Vol. 23, 1997, pp. 81-94. doi:10.1016/S0360-1285(97)00006-3

[7] Plessing, T., Peters, N., and Wünning, J. G., "Laseroptical Investigation of Highly Preheated Combustion with Strong Exhaust Gas Recirculation," Proceedings of the Combustion Institute, Vol. 27, 1998, pp. 3197-3204. doi:10.1016/S0082-0784(98)80183-5

[8] Lückerath, R., Schütz, H., Noll, B., and Aigner, M., "Experimental Investigations of FLOX ${ }^{\circledR}$ Combustion at High Pressure," Proceedings of the Flameless Combustion Workshop [CD-ROM], Lund Univ., Lund, Sweden, 2005.

[9] Lückerath, R., Meier, W., and Aigner, M., "FLOX® Combustion at High Pressures With Different Fuel Compositions," Journal of Engineering for Gas Turbines and Power, Vol. 130, 2008, pp. 011505 $1-7$. doi: $10.1115 / 1.2749280$

[10] Mongia, H. C., "Flameless Combustion for Ultralow Emissions Propulsion Engine Combustors," Proceedings of the Flameless Combustion Workshop [CD-ROM], Lund Univ., Lund, Sweden, 2005.

[11] Guillou, E., Cornwell, M., and Gutmark, E., "Application of 'Flameless' Combustion for Gas Turbine Engines," 47th AIAA Aerospace Sciences Meeting, Orlando, FL, AIAA Paper 2009-225, 2009.

[12] Najm, H. N., Paul, P. H., Mueller, C. J., and Wyckoff, P. S., "On the Adequacy of Certain Experimental Observables as Measurements of Flame Burning Rate," Combustion and Flame, Vol. 113, 1998, pp. 312332. doi:10.1016/S0010-2180(97)00209-5

[13] Eckbreth, A. C., Laser Diagnostic for Combustion Temperature and Species, Gordon and Breach, The Netherlands, 1996, pp. 526-586.

[14] Kohse-Höinghaus, K., and Jeffries, J. (eds.), Applied Combustion Diagnostics, Taylor and Francis, New York, 2002, pp. 194-286.

[15] Ax, H., Stopper, U., Meier, W., Aigner, W., and Güthe, F., "Experimental Analysis of the Combustion Behaviour of a Gas Turbine Burner by Laser Measurement Techniques," ASME Turbo Expo: Power for Land, Sea and Air, Orlando, American Soc. of Mechanical Engineers Paper GT2009-59171, Fairfield, NJ, 2009.

[16] Stopper, U., Aigner, M., Meier, W., Sadanandan, R., Stöhr, M., and Kim, I. S., "Flow Field and Combustion Characterization of Premixed Gas Turbine Flames by Planar Laser Techniques," Journal of Engineering for Gas Turbines and Power, Vol. 131, 2009, pp. 021504 1-8. doi:10.1115/1.2969093

[17] Dhanuka, S. K., Temme, J. E., Driscoll, J. F., and Mongia, H. C., "Vortex Shedding and Mixing Layer Effects on Periodic Flashback in a Lean Premixed Prevaporized Gas Turbine Combustor," Proceedings of the Combustion Institute, Vol. 32, 2009, pp. 2901-2908. doi:10.1016/j.proci.2008.06.155
[18] McDonnel, V. G., and Samuelsen, G. S., "Measurement of Fuel Mixing and Transport Processes in Gas Turbine Combustion," Measurement Science and Technology, Vol. 11, 2000, pp. 870-886. doi:10.1088/0957-0233/11/7/304

[19] Locke, R. J., Hicks, Y. R., Anderson, R. C., and Zaller, M. M., "Optical Fuel Injector Patternation Measurements in Advanced Liquid-Fueled, High Pressure, Gas Turbine Combustors," Combustion Science and Technology, Vol. 138, 1998, pp. 297-311. doi: $10.1080 / 00102209808952073$

[20] Flamme, M., Al-Halbouni, A., Wünning, J. G., Scherer, V., Schlieper, M., Aigner, M., Lückerath, R., Noll, B., Stöhr, R., and Binninger, B., "Low Emission Gas Turbine Combustors Based on Flameless Combustion," European Combustion Meeting Paper 45, Orleans, France, 2003.

[21] Dandy, D. S., and Vosen, S. R., "Numerical and Experimental Studies of Hydroxyl Radical Chemiluminescence in Methane-Air Flames," Combustion Science and Technology, Vol. 82, 1992, pp. 131-150. doi:10.1080/00102209208951816

[22] Nori, V., "Modelling and Analysis of Chemiluminescence Sensing for Syngas, Methane and Jet-A Combustion," Ph.D. Dissertation, School of Aerospace Engineering, Georgia Inst. of Technology, Atlanta, GA, 2008.

[23] Warnatz, J., Maas, U., and Dibble, R. W., Combustion, 4th ed., Springer-Verlag, Berlin, 2006, pp. 259-267.

[24] Correa, S. M., "A Review of $\mathrm{NO}_{x}$ Formation Under Gas-Turbine Combustion Conditions," Combustion Science and Technology, Vol. 87, 1993, pp. 329-362. doi:10.1080/00102209208947221

[25] Schütz, H., Lückerath, R., Kretschmer, T., Noll, B., and Aigner, M., "Analysis of the Pollutant Formation in the FLOX® Combustion," Journal of Engineering for Gas Turbines and Power, Vol. 130, 2008, Paper 011503. doi:10.1115/1.2747266

[26] Guethe, F., Garcia, M., and Burder, A., "Flue Gas Recirculation in Gas Turbine: Investigation of Combustion Reactivity and NOx Emission," ASME Turbo Expo: Power for Land, Sea and Air, Orlando, FL, American Soc. of Mechanical Engineers Paper GT2009-59221, Fairfield, NJ, 2009.

[27] Sadanandan, R., Stöhr, M., and Meier, W., "Simultaneous OH-PLIF and PIV Measurements in a Gas Turbine Model Combustor," Applied Physics, B. Lasers and Optics, Vol. 90, 2008, pp. 609-618. doi:10.1007/s00340-007-2928-8

[28] Drake, M. C., Pitz, R. W., Lapp, M., Fenimore, C. P., Lucht, R. P., Sweeney, D. W., and Laurendeau, N. M., "Measurements of Superequilibrium Hydroxyl Concentrations in Turbulent Non-Premixed Flames Using Saturated Fluorescence," Proceedings of the Combustion Institute, Vol. 20, 1985, pp. 327-335. doi:10.1016/S0082-0784(85)80518-X

[29] Barlow, R. S., Dibble, R. W., Chen, J.-Y., and Lucht, R. P., "Effect of Damköhler Number on Superequilibrium $\mathrm{OH}$ Concentration in Turbulent Non-Premixed Jet Flames," Combustion and Flame, Vol. 82, 1990, pp. 235-251. doi:10.1016/0010-2180(90)90001-8

[30] Drake, M. C., Ratcliffe, J. W., Blint, R. J., Carter, C. D., and Laurendeau, N. M., "Measurements and Modeling of Flamefront NO Formation and Superequilibrium Radical Concentrations in Laminar High-Pressure Premixed Flames," Proceedings of the Combustion Institute, Vol. 23, 1991, pp. 387-395. doi:10.1016/S0082-0784(06)80283-3

[31] Driscoll, J. F., "Turbulent Premixed Combustion: Flamelet Structure and its Effect on Turbulent Burning Velocities," Progress in Energy and Combustion Science, Vol. 34, 2008, pp. 91-134. doi:10.1016/j.pecs.2007.04.002

[32] Dally, B. B., Riesmeier, E., and Peters, N., "Effect of Fuel Mixture on Moderate and Intense Low Oxygen Dilution Combustion," Combustion and Flame, Vol. 137, 2004, pp. 418-431. doi:10.1016/i.combustflame.2004.02.011

[33] Rao, G. A., Levy, Y., and Gutmark, E. J., "Chemical Kinetic Analysis of a Flameless Gas Turbine Combustor," Proceedings of ASME Turbo Expo: Power for Land, Sea and Air, Berlin, American Soc. of Mechanical Engineers Paper GT2008-50619, Fairfield, NJ, 2008.

[34] Özdemir, I. B., and Peters, N., "Characteristics of the Reaction Zone in a Combustor Operating at Mild Combustion," Experiments in Fluids, Vol. 30, 2001, pp. 683-695. doi: $10.1007 / \mathrm{s} 003480000248$ 